Sādhanā Vol. 30, Part 1, February 2005, pp. 21-46. @ Printed in India

\title{
Ion cyclotron resonance heating system on Aditya
}

\author{
D BORA ${ }^{1}$, SUNIL KUMAR ${ }^{1}$, RAJ SINGH ${ }^{1}, \mathrm{~S}$ V KULKARNI ${ }^{1}$, \\ A MUKHERJEE ${ }^{1}, \mathrm{~J} \mathrm{P} \mathrm{SINGH}^{1}$, RAGURAJ SINGH ${ }^{1}, \mathrm{~S}_{\mathrm{NANI}}{ }^{1}$,

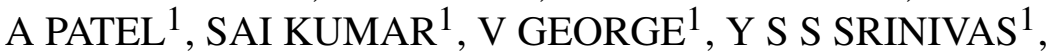 \\ P KHILAR $^{1}$, M KUSHWAH $^{1}$, P SHAH ${ }^{1}$, H M JADAV $^{1}$, \\ RAJNISH KUMAR ${ }^{1}$, S GANGOPADHYAY $^{1}$, H MACHHAR $^{1}$, \\ B KADIA $^{1}$, K PARMAR $^{1}$, A BHARDWAJ ${ }^{1}$, SURESH ADAV ${ }^{1}$, \\ D RATHI $^{1}$ and D S BHATTACHARYA ${ }^{2}$
}

\author{
${ }^{1}$ Institute for Plasma Research, Bhat, Gandhinagar 382 428, India \\ ${ }^{2}$ Variable Electron Cyclotron Centre, Kolkata, India \\ e-mail: apu@ipr.res.in
}

MS received 26 August 2003; revised 4 May 2004

\begin{abstract}
An ion cyclotron resonance heating (ICRH) system has been designed, fabricated indigenously and commissioned on Tokamak Aditya. The system has been commissioned to operate between 20.0 and $47.0 \mathrm{MHz}$ at a maximum power of $200 \mathrm{~kW}$ continuous wave $(\mathrm{CW})$. Duration of $500 \mathrm{~ms}$ is sufficient for operation on Aditya, however, the same system feeds the final stage of the $1.5 \mathrm{MW}$ ICRH system being prepared for the steady-state superconducting tokamak (SST-1) for a duration of $1000 \mathrm{~s}$. Radio frequency (RF) power $(225 \mathrm{~kW})$ has been generated and successfully tested on a dummy load for $100 \mathrm{~s}$ at $30.0 \mathrm{MHz}$. Lower powers have been coupled to Aditya in a breakdown experiment. We describe the system in detail in this work.
\end{abstract}

Keywords. Tokamak; ICRH; radio frequency, magnetosonic wave, second harmonic heating.

\section{Introduction}

A tokamak is a magnetically confined device with high temperature plasma to reach ignition for the generation of thermonuclear power. The plasma of a tokamak cannot be heated to ignition using ohmic heating alone, since joule-heating efficiency decreases with increase in plasma temperature and the maximum value of plasma current is limited by the onset of magneto-hydrodynamic instabilities that terminate the discharge. Auxiliary heating therefore is essential to achieve the goal.

Radio frequency (RF) heating of tokamak plasmas is one of the most successful auxiliary heating schemes at present. Different frequency ranges have been tried in different experiments. Ion cyclotron resonance frequency (ICRF) range has been very successfully used up to multi-megawatt power levels in tokamaks. 
Fast magnetosonic waves (compressional Alfven waves) do not resonate at the cyclotron frequency, but propagate above and below this frequency. The fast waves are right-circularly polarized and do not couple energy to the ions in a purely single species plasma. However, in the presence of a minority species, very efficient heating has been observed. Three regimes have been found that enable efficient coupling of RF energy to the ions. They are as follows.

(i) Minority fundamental heating,

(ii) ion-ion hybrid heating, and

(iii) second harmonic heating of a single species plasma.

Power absorbed to the plasma particles varies from machine to machine. Till now the maximum absorbed power in the ion cyclotron frequency range is $24 \mathrm{MW}$, while $32 \mathrm{MW}$ was launched from the generator (JET result).

An auxiliary RF heating system to raise the plasma temperature at the ion cyclotron resonance frequency has been commissioned on Tokamak Aditya (Bhatt et al 1989). The auxiliary launched power (of the electromagnetic waves) must eventually be transferred to the bulk of the plasma and ultimately to the fuel-ion components of the plasma if fusion reactions are to take place. Thermalization of the external energy usually takes place through collisional processes. The injected fast particles or the particles accelerated by the electromagnetic field transfer their energy to the plasma background through collisions. In the case of wave heating, this process occurs indirectly through waves (Alfven, lower-hybrid etc) or particle (Landau, cyclotron) resonances that are basically non-collisional processes. These non-collisional processes cause velocity space diffusion of the particle that is counterbalanced by the collisions that tend to restore a Maxwellian distribution. Wave heating methods can create very energetic particles for which collisions are negligible. In such cases the magnetic field should be very strong to confine energetic particles.

Among all wave-heating schemes, ion cyclotron frequency heating (ICRH) appears to be most attractive both in terms of physics and technology. First significant experimental results on plasma heating by wave coupling in the ion cyclotron frequency range were obtained in 1974 in TM1-RF (Vdovin et al 1974) and in ST tokamak (Adam et al 1974) where appreciable heating of a deuterium plasma was observed for frequencies in the vicinity of $\omega=2 \Omega_{D}$, where $\omega$ is launched frequency and $\Omega_{D}$ denotes cyclotron frequency for deuterium plasma.

The system is broadly divided into the following sub-systems:

- Radio frequency (RF) generator

- Transmission line

- Interface

- Antenna

- Electrical DC power supplies

- Data acquisition and control (DAC) system.

In this paper, we describe the subsystems that constitute the ICRH system on Aditya. The second section of this report is a description on indigenously built $200 \mathrm{~kW}$ RF generator. It also presents the necessary operating source frequency depending on the toroidal magnetic field and requirement of RF power to raise plasma temperature. Detailed design of various components of transmission line is presented in $\S 3$. Section 4 discusses the design of the vacuum transmission line, called interface. High power fast wave antenna design is described in $\S 5$. This section also deals with thermal loads on antenna during operation, impurity generation and electromagnetic stresses due to plasma disruption. Different kinds of DC 
Table 1. Operating frequencies vs. magnetic fields.

Gas used: $\mathrm{H}_{2}$

\begin{tabular}{lcrrr}
\hline$B_{T}(\mathrm{~T})$ & 0.75 & 0.9 & 1.0 & 1.2 \\
$2 f_{C H}(\mathrm{MHz})$ & 22.8 & 27.4 & 30.4 & 36.5 \\
\hline
\end{tabular}

power supplies required for $200 \mathrm{~kW}$ modular RF generator are described in $\S 6$. Section 7 discusses data acquisition and control for the ICRH system. Initial experimental results on plasma load are reported in $\S 8$.

\section{RF generator}

Requirements for RF generators for fusion research include high power, long pulse duration and reliability. The design of the RF generator is based on the requirements for heating plasmas with various ion species, plasma parameters and magnetic fields.

The required frequency $f$ is considered keeping in mind the toroidal magnetic field at the plasma centre. In Aditya tokamak the field value is varied between $0.75 \mathrm{~T}$ and $1.2 \mathrm{~T}$. Table 1 shows the operating frequencies for different magnetic fields.

Minimum power requirement is estimated to fix output power from the RF generator. From the consideration of the power balance equation, the expected plasma temperature (Dolan 1982) is,

$$
0 \cdot 024\left\langle n\left(T_{e}+T_{i}\right)\right\rangle / \tau_{E}=\left(P_{\text {in }}-P_{r}\right) / V_{p} .
$$

Assuming $P_{r} \approx 0.3 P_{\text {in }}$ and $T_{i} \approx 0.4 T_{e}$ we get,

$$
\left\langle T_{e}\right\rangle=\left(0.7 P_{\mathrm{in}} \tau_{E}\right) /\left(0.034\left\langle n_{20}\right\rangle V_{p}\right) .
$$

We have calculated energy confinement time using ITER89-P L-mode scaling (Uckan et al 1990) and is given by:

$$
\tau_{E}=0.048 I^{0 \cdot 85}\left\langle n_{20}\right\rangle^{0 \cdot 1} a^{0 \cdot 3} R_{o}^{1 \cdot 2} A_{i}^{0 \cdot 5} P_{\text {in }}^{-0 \cdot 5} \kappa_{x}^{0 \cdot 5} B^{0 \cdot 2},
$$

where,

$\tau_{E}=$ energy confinement time (s),

$T_{e}=$ electron temperature $(\mathrm{keV})$,

$P_{O H}=$ ohmic power $=V_{\text {loop }} I_{p}(\mathrm{MW})$,

$P_{r}=$ radiative power $(\mathrm{MW})$, and

$\tau_{E}=3.9 \mathrm{~ms}, \quad T_{e}=432 \mathrm{eV}, \quad T_{i}=173 \mathrm{eV}$,

where, $P_{\text {aux }}=0.2 \mathrm{MW}$ and $P_{O H}=0.2 \mathrm{MW}$.

Thus, to raise the temperature at least by $0.4 \mathrm{keV}$ and maintain it at that level, we fix the $\mathrm{RF}$ power requirement at $200 \mathrm{~kW}$. Hence, the RF generator for ICRH system on Aditya is designed to fulfill the specifications given in table 2.

The ICRH generator (figure 1) for Aditya consists of a low power oscillator, RF switch, modulator switch, RF attenuator, three stages of solid state low power amplifiers, three stages 
Table 2. Specifications for the RF generator for Aditya ICRH system.

\begin{tabular}{lc}
\hline Parameter & ICRH system specifications \\
\hline CWRF power & $200 \mathrm{~kW}(\max )$ \\
Radio frequencies & 20 to $40 \cdot 0 \mathrm{MHz}$ \\
Harmonic content & $-30 \mathrm{dBc}$ \\
RF pulse duration & $100 \mathrm{~ms}$ \\
\hline
\end{tabular}

of power grid and tube high power amplifiers. All the stages of the generator are designed to cover 20 to $40 \mathrm{MHz}$ frequency range for the Aditya ICRH experiments.

One additional chain that covers 22.8 to $45.6 \pm 1 \mathrm{MHz}$ is designed to drive the $1.5 \mathrm{MW}$ output final stage of the SST-1 ICRH CW RF generator. The same also acts as a spare for the Aditya ICRH generator. A description of each section of the $200 \mathrm{~kW}$ RF generator is given in the next section.

\subsection{Section I: B1, B2 B3, B4 and B5 - CWRF oscillator, buffer, RF switch, modulator and attenuator}

The tunable Collpit oscillator (figure 2) using a transistor 2N2222A gives out CW RF of $4 \mathrm{~mW}$ max within 20 to $47 \mathrm{MHz}$ by means of a variable parallel plate capacitor. In-built closed loop buffer AD9630 at the output provides constant load and stability to the oscillator. The surface mountable RF switch PSW1111, the modulator switch PSW1111 and the RF attenuator PAS3 from mini-circuits are used in series along with the CW RF oscillator on the same PCB. The RF switch PSW-1111 needs $+5 \mathrm{~V}$ to switch ON with rise/fall time of less than $4 \mu \mathrm{s}$. RF attenuator PAS-3 acts to vary the output power of the oscillator from $0.5 \mathrm{mw}$ to $4.0 \mathrm{mw}$ by using a $0-20 \mathrm{~mA}$ DC current source. It controls the amplified output power within $10 \mathrm{~dB}$. Another buffer amplifier AD9360 is used on the same PCB to minimize the effects of loading.

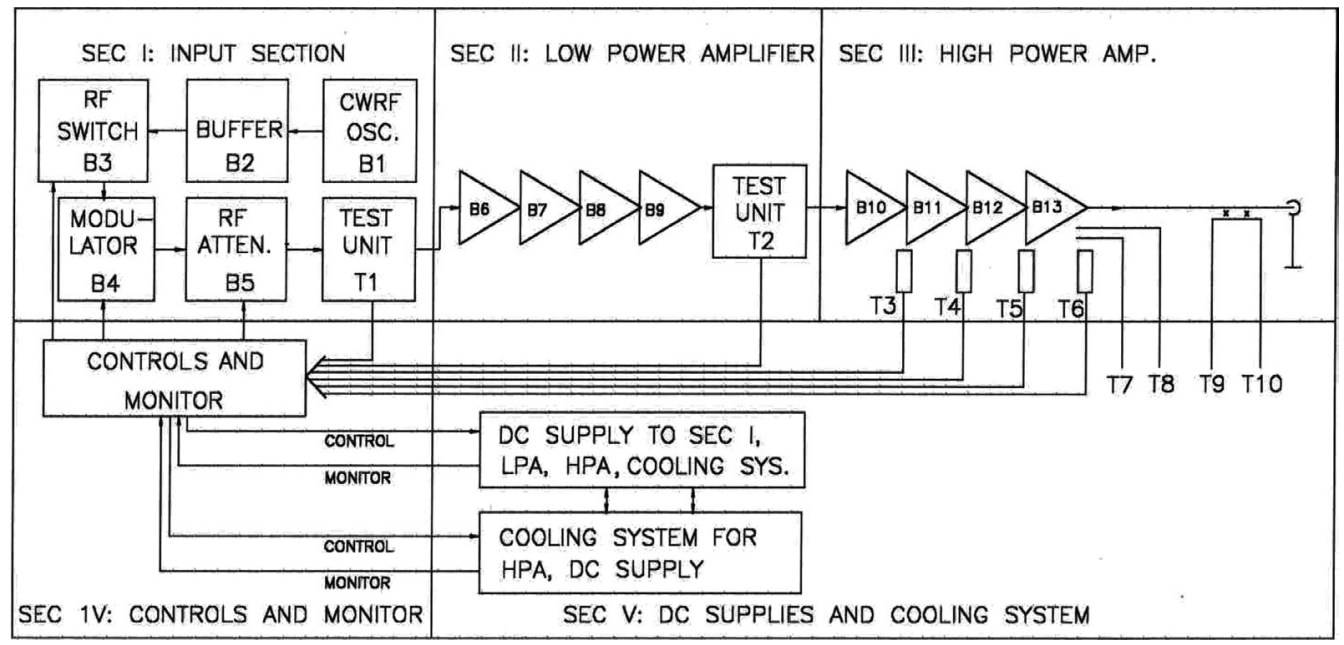

Figure 1. Schematic of ICRH generator in Aditya. 


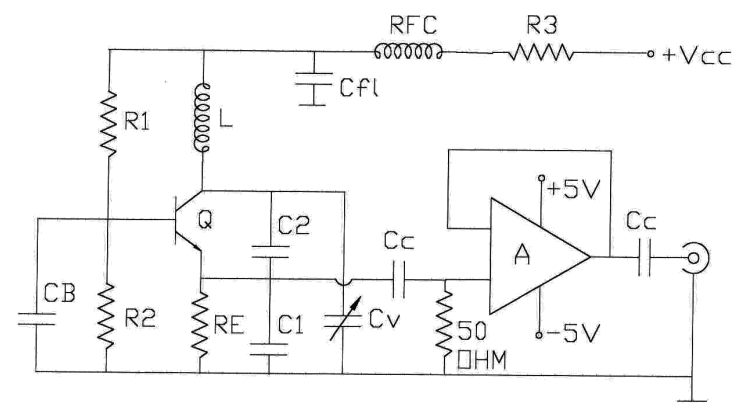

Figure 2. CW RF Collpi oscillator.

\subsection{Section II: B6, B7 and B8: Low power solid state amplifier}

The CW RF input of $4 \mathrm{~mW}$ maximum from the shielded box containing section I is available to the three stages of LPA (figures 3a-c) made around transistors 2N3375A, 2N3733A and $2 \mathrm{~N} 5071 \mathrm{~A}$. It provides a CW RF output of about 22 to $28 \mathrm{~W}$ maximum in the frequency range of 20 to $47 \mathrm{MHz}$.

\subsection{Section III: B10, B11 and B12 - Pre-driver, driver and output stages of HPA}

Output of pre-driver (triode 3CX5000A7) grounded grid amplifier is made tunable within 20 to $47 \mathrm{MHz}$ by using a variable coil and a vacuum variable capacitor (VVC), whereas the input circuit is broadband (figure 4 ). The cathode is passively biased at $+25 \mathrm{~V}$. Impedance matching of the plate is taken care of by the RFC, which also acts as RF auto transformer. While operating at $3.0 \mathrm{kV} / 0.6 \mathrm{~A}$, the $\mathrm{CW}$ RF output is observed to vary from $700 \mathrm{~W}$ to $1.0 \mathrm{~kW}$
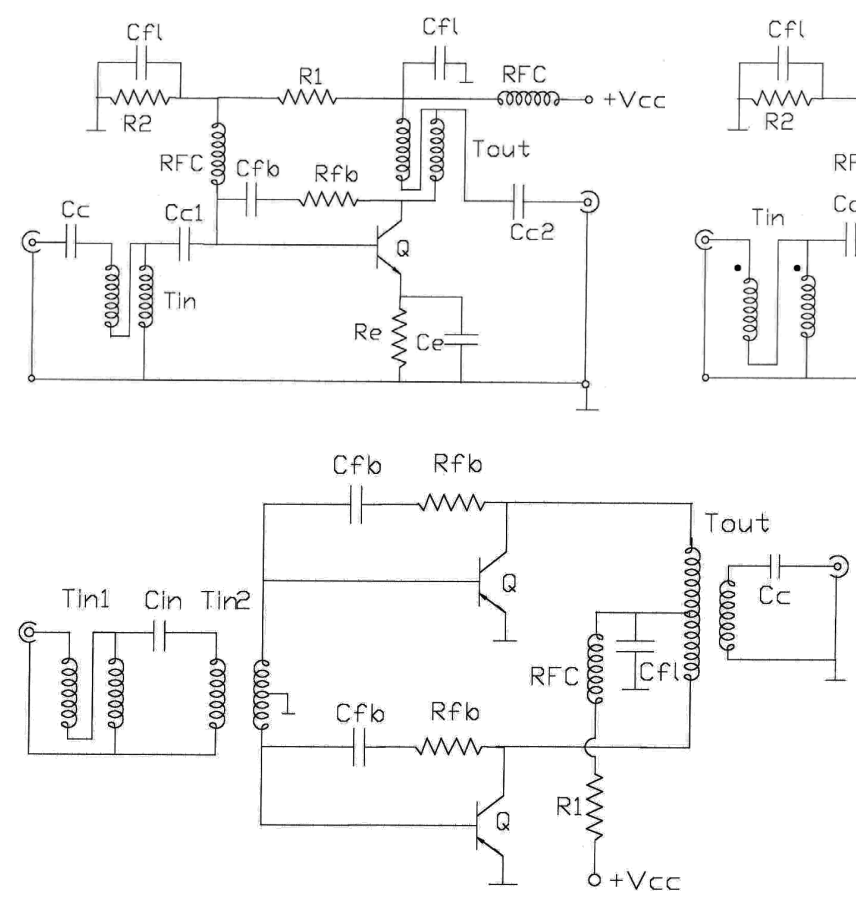

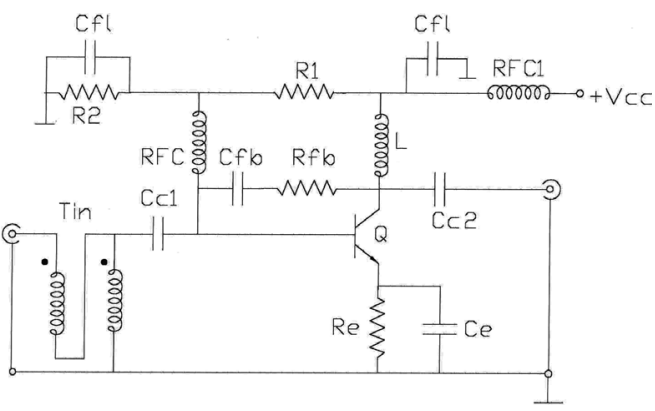

Figure 3. First (a), second (b) and third (c) stages of the low power solid state amplifier. 


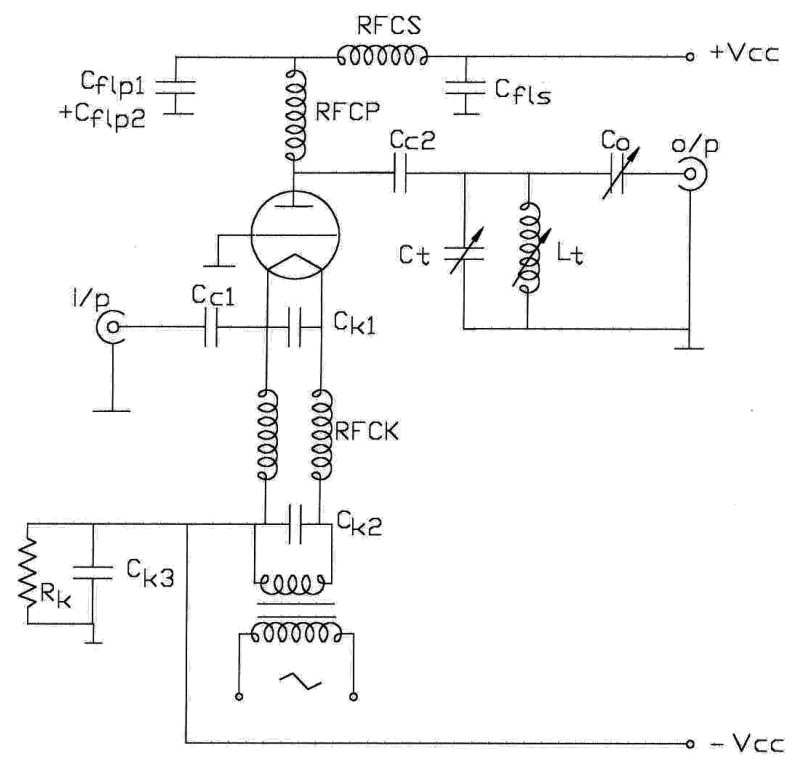

Figure 4. Circuit diagram for predriver and driver stages.

with efficiency $\sim 48 \%$, gain $\sim 15.5 \mathrm{~dB}$ in class $\mathrm{AB}$ mode for an input varying from 20 to $24 \mathrm{~W}$ at different frequencies in between 20 and $47 \mathrm{MHz}$.

Output circuit of the driver (triode $3 \mathrm{CW} 30000 \mathrm{H} 7$ ) grounded grid amplifier is made tunable within 20 to $47 \mathrm{MHz}$ by using a variable coil and a VVC whereas the input circuit is broadband (figure 4 ). The cathode is passively biased at $+50 \mathrm{~V}$. Impedance matching of the plate is taken care of by the RFC, which also acts as RF transformer. While operating at $6.0 \mathrm{kV} / 3.5 \mathrm{~A}$, the CW RF output is observed varying from $9 \mathrm{~kW}$ to $15 \mathrm{~kW}$ with efficiency $\sim 50 \%$, gain $\sim 15.0 \mathrm{~dB}$ in class $\mathrm{AB}$ mode for an input varying from $700 \mathrm{~W}$ to $1.0 \mathrm{~kW}$ at different frequencies between 20 and $47 \mathrm{MHz}$.

The output stage of the Aditya ICRH generator or driver stage of the SST-1 ICRH generator for up to $46.6 \mathrm{MHz}$ (figure 5) uses tetrode 4CM300000GA. The output cavity is tunable with a movable-shorting plunger. Plate blocking $4 \mathrm{kpF}$ capacitor is a array of eight $500 \mathrm{pF}$ capacitors. The output resistance of $238 \Omega$ to $358 \Omega$ is matched to $50 \Omega$ with a series coupled VVC. Distributed components are used for making input and output cavities. The screen grid is kept at the RF ground and control grid at DC ground. The T-section transmission line network matches the $50 \Omega$ with input impedance of $6 \cdot 25 \Omega$ to $10 \Omega$ at a maximum of $10 \mathrm{~kW}$. It uses a shunt $\mathrm{VVC}$ of 100 to $1000 \mathrm{pF}$ to cancel the reactive part. This stage is tested at $13 \mathrm{kV} / 22 \mathrm{~A}$ with CWRF input of $\sim 10 \mathrm{~kW}$. Output power $\sim 200 \mathrm{~kW} / 10 \mathrm{~S}$ is observed at $29 \mathrm{MHz}$ against the tunable range of $20-47 \mathrm{MHz}$ (figure 6). RF power stability of $0 \cdot 1 \%$ for $500 \mathrm{~ms}$ is observed in $200 \mathrm{~kW}$ stage.

All the stages have intensive cooling to accommodate for $\mathrm{CW}$ operation. The filament for all the stages is cooled using high-pressure blowers. Maximum capacity blower is attached with $200 \mathrm{~kW}$ stage. Ait at $200 \mathrm{cfm}$ at $30^{\circ} \mathrm{C}$ is forced through the socket in the $200 \mathrm{~kW}$ stage from a high-pressure blower at a backpressure of $250 \mathrm{MWG}$. Anodes for the $20 \mathrm{~kW}$ and $200 \mathrm{~kW}$ stages are cooled using forced water. For full-rated anode dissipation of $20 \mathrm{~kW}$ and $200 \mathrm{~kW}$, $35 \mathrm{lpm}$ and $150 \mathrm{lpm}$ of water at $40^{\circ} \mathrm{C}$ inlet temperature are passed through the anode cooler jackets respectively. 


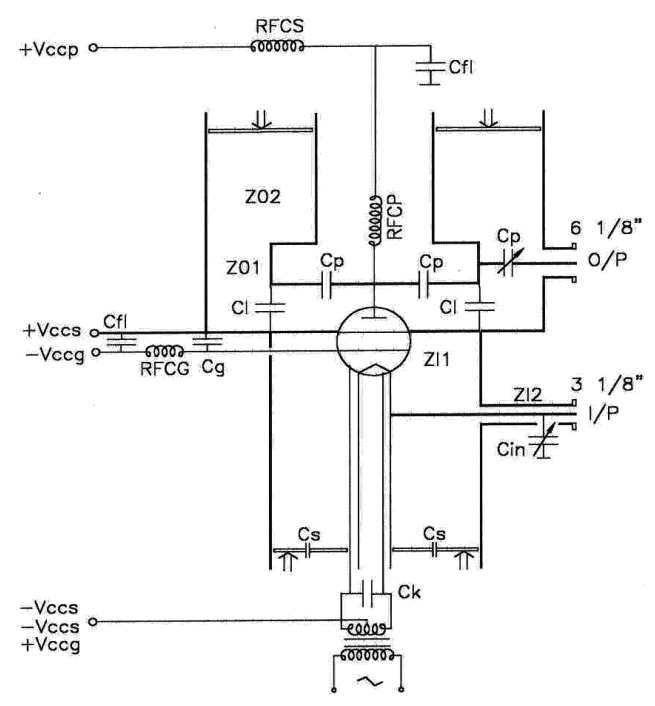

Figure 5. Circuit diagram for output stage of Aditya ICRH generator.

A dummy load of $1.5 \mathrm{MW} / 50 \Omega$ (Thomcast made) serves as the load for testing the $200 \mathrm{~kW}$ amplifier. The power dissipated in the dummy load can be determined on a calorimetric basis by means of thermometers incorporated in the soda water circuit and the soda water flowmeter. The most important component in the closed soda water circuit is the resistance element, which in conjunction with the screens, gives a constant impedance over $30 \mathrm{~Hz}$ to $100 \mathrm{MHz}$ frequency range. The soda water circuit is thermostatically controlled by means of a motor-driven regulating valve built in the cooling circuit, such that the mean temperature of the soda water remains constant. Main specifications for the dummy load are as follows.

Maximum power dissipation:

Resistance:

Frequency range:

Cooling circuit:

SWR (at operating temperature) up to:

Flow rate:

Pump consumption:

Total quantity of soda water:

\section{$1.5 \mathrm{MW}$}

$50 \mathrm{ohms}$, asymmetrical

$30 \mathrm{~Hz}-100 \mathrm{MHz}$

$1.5 \mathrm{MW}$

$26 \mathrm{MHz} \leq 1 \cdot 1$

$100 \mathrm{MHz} \leq 1 \cdot 2$

$60 \mathrm{~m}^{3} / \mathrm{h}$

$6.5 \mathrm{~kW}$

15001 (approx.)

No extra lead inductance is included in the dummy load connection during amplifier testing.

RF generator may radiate undesired electromagnetic (EM) energy if it is not properly shielded. This EM radiation may interfere with other sensitive devices, systems and equipments, which in turn show malfunctioning. Electromagnetic interference can occur via conducted or radiated interference. The conducted interference is due to power line, signal line etc. passing in the vicinity of the RF generator, which is avoided by using RF filters and feedthroughs connected to the cables coming in and out of the generator rack. The radiated interference is due to EM fields through space. This being a source of EM interference, all the stages of the $200 \mathrm{~kW}$ RF generator are shielded by using shielded enclosure. Three sides of the enclosure are brazed/welded to avoid RF leakage and the front side of the enclosure is kept 
(a)

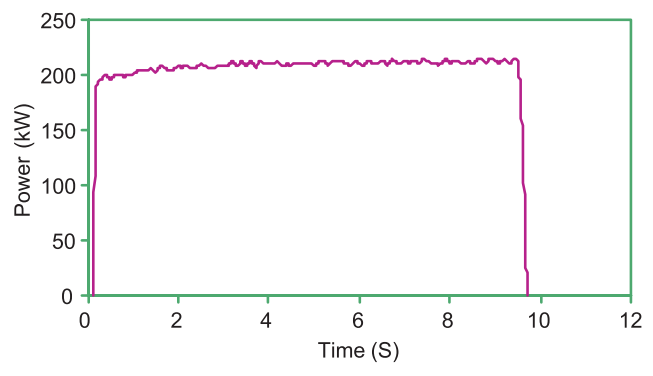

(c)

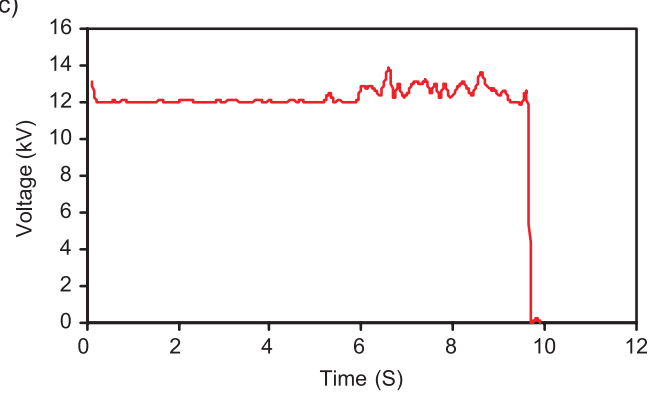

(e)

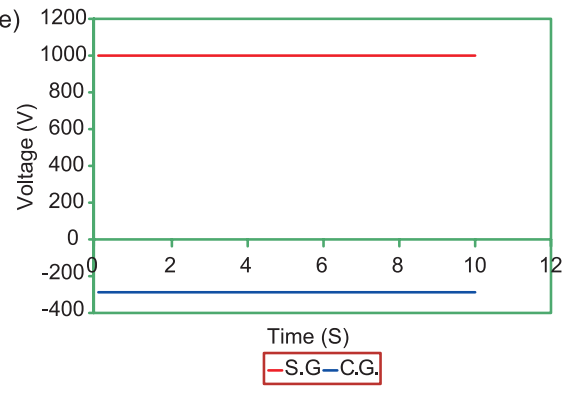

(b)

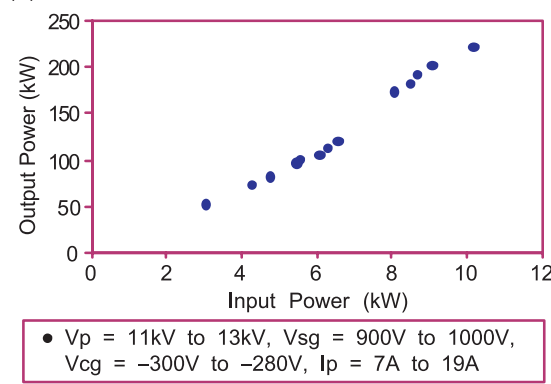

(d)
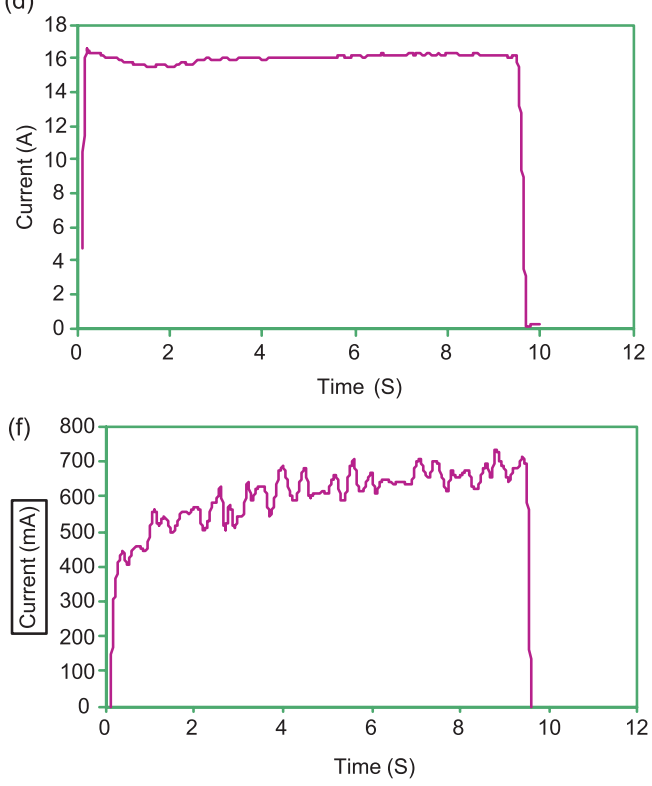

Figure 6. Test results for $200 \mathrm{~kW}$ amplifier at $29 \mathrm{MHz}$. (a) Power output (shot No. 28, at 29 MHz), (b) Test results of $200 \mathrm{~kW}$ amplifier at $29 \mathrm{MHz}$, (c) Plate voltage (shot No. 28, at $29 \mathrm{MHz}$ ), (d) Plate current (shot No. 28, at $29 \mathrm{MHz}$ ), (e) S.G. \& C.G. voltages (shot No. 28, at $29 \mathrm{MHz}$ ), (f) S.G. current (shot No. 28, at $29 \mathrm{MHz}$ ).

in spring-loaded contact for necessary servicing. Output cavity resonator for $200 \mathrm{~kW}$ stage, which is fabricated locally, is made using double-shielded enclosure. Radiation level is monitored during the testing period, which is always in the acceptable range, around $1 \mathrm{~mW} / \mathrm{cm}^{2}$ at $1 \mathrm{~m}$ distance from the generator.

\section{Transmission line}

RF transmission line is used to transfer RF power from the RF generator to the antenna placed inside the tokamak vessel. The approximate length of the transmission line from the RF generator to antenna placed in Tokamak Aditya in the experimental hall is about $53 \mathrm{~m}$. At the end of the transmission line, $97 \%$ transmission with $3 \%$ insertion loss is observed. A view of the transmission line in the tokamak hall is shown in figure 7. 


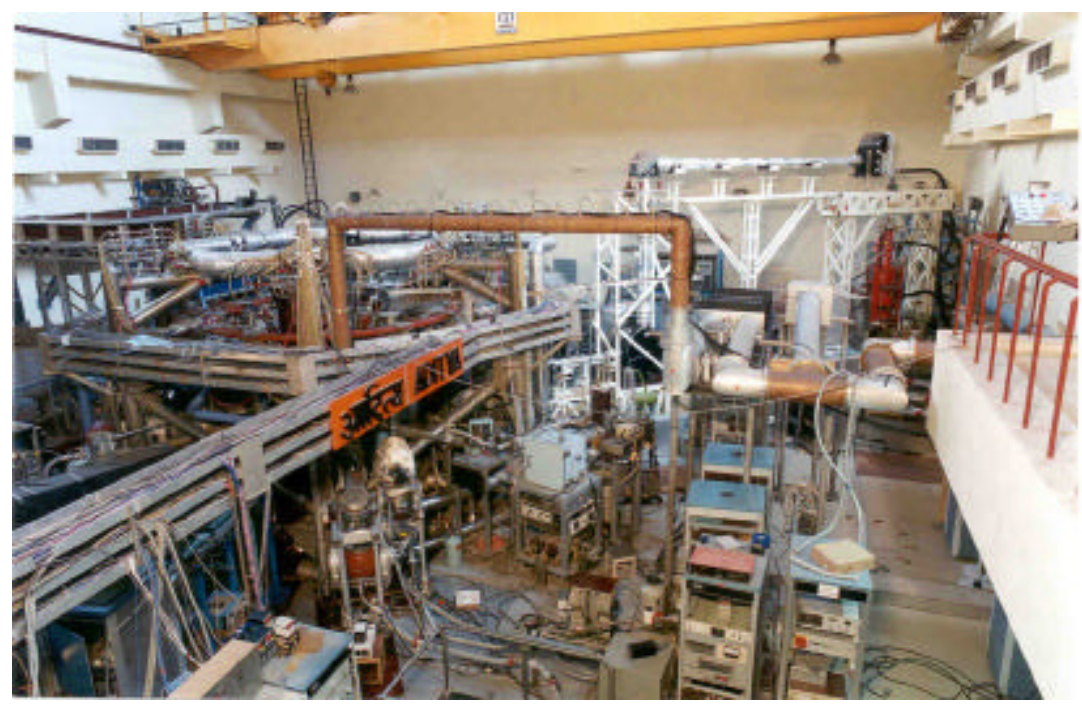

Figure 7. View of transmission line in the tokamak hall.

The transmission line consists of the following sub systems.

- Main co-axial line of 6" and 9" type [1 inch $(1 ")=2.54 \mathrm{~cm}]$.

- Various elbows of 6" and 9" type.

- Gas barriers of 6" type.

- Probe section.

- Directional couplers.

- Fixed and variable phase shifters.

- Variable stubs.

- Reducers of 6" to 9", 6" to 8" type.

- 9" tee's.

The above transmission line has been installed along with the other components and is tested and commissioned for regular operations on Aditya and the dummy load.

\subsection{Main co-axial line of 6" and 9" type, elbows and gas barrier}

Most of the components are indigenous. Co-axial line consists of inner conductor, outer conductor, inner conductor joints, flanges and teflon supports for inner conductor. The transmission line between second stub and antenna is of 9" size. The size of the line here is bigger because voltage standing wave ratio (VSWR) is higher in this region. The transmission line from second stub to generator is of 6" size. The copper tubes used for main transmission line are of ETP hard drawn type. The line has been tested and an efficiency of $97 \%$ has been achieved for a length of $50 \mathrm{~m}$. This efficiency includes all the losses, i.e. Ohmic losses for inner and outer conductor, loss at inner conductor joints, reflection loss etc. The distributed values of inductance and capacitance are $167 \mathrm{nH} / \mathrm{m}$ and $66.7 \mathrm{pF} / \mathrm{m}$ for this transmission line. Dielectric losses are very small because overall dielectric volume is very small.

Elbows have been used at different places. These are of 6" and 9" size. Elbows have been designed in-house and fabricated locally. These elbows are of the miter type, which give 
better VSWR. The impedance offered by elbows is of the order of $49.2 \mathrm{ohm}$ at $40 \mathrm{MHz}$ for both 6" and 9" type. Two gas barriers have been put in the line in order to pressurise the line. These gas barriers are of 6" type and can go upto 3 bar of gauge pressure. These are of the $50 \mathrm{ohm}$ type. Gas barriers have been designed at IPR and fabricated in IPR workshop. They have been successfully tested at $220 \mathrm{~kW} \mathrm{CW}$.

\subsection{Probe section}

Twenty probes have been mounted on a section of transmission line of length $3.75 \mathrm{~m}$. This section is used to find the VSWR curve. This curve helps in determining the plasma impedance. The number of probes have been chosen as 20 in order to get fairly good replica of the VSWR curve. The probes have been tested for both capacitive as well as inductive loads. The measurements have an error of the order of $8-10 \%$.

\subsection{Directional coupler}

Two directional couplers have been used in order to find reflected and incident power, one on the side of the load while the other one is on the side of the generator. Both are of 6" type. These directional couplers use current loops in order to pick up the signal giving the information on power. Indigenously made directional couplers have been calibrated for different values of known loads at different frequencies. A maximum error of about $12 \%$ has been measured. The results have been shown in figure 8 .

\subsection{Variable phase shifter}

There is one variable phase shifter of 3.0-m phase shifter length. The co-axial line size used is 9". It is motor driven and is controlled by DAC system. Appropriate signal is sent from DAC to move it to required position. It has 50-ohm characteristic impedance. It has been put about $8.5 \mathrm{~m}$ from antenna. This is the optimized position for $20-47 \mathrm{MHz}$ frequency range. The probe section has been put between phase shifter and antenna.

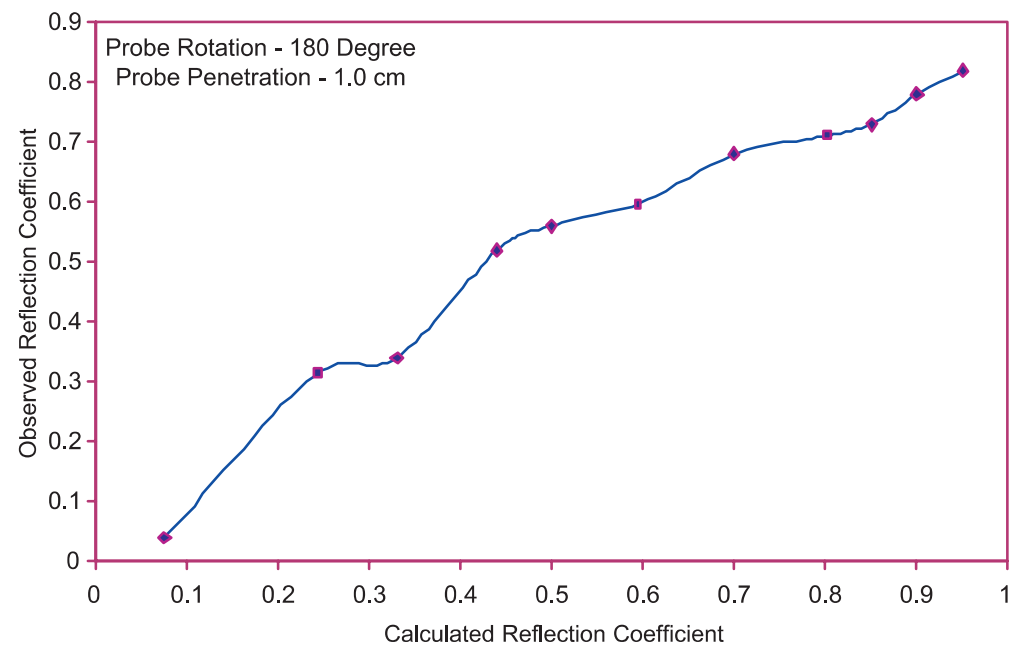

Figure 8. Calibration results for directional coupler. 


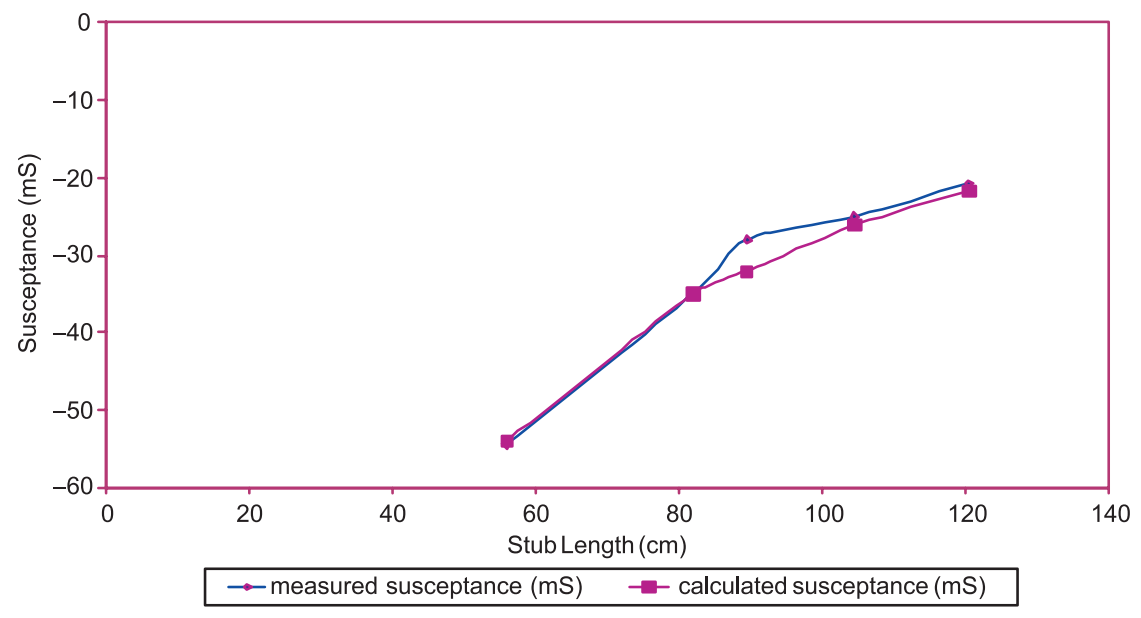

Figure 9. Variation of stub susceptance at $30 \mathrm{MHz}$.

\subsection{Tee}

Tees are used to connect stubs to the main transmission line. There are two tees of 12 " arm length each inserted into the line. The tees are of 9" type and $50 \mathrm{ohm}$ characteristic impedance.

\subsection{Variable stub}

Two variable stubs are used. One has a variable length of $3.0 \mathrm{~m}$, while the other has variable length of $1.5 \mathrm{~m}$ variable. Both the stubs are motor-driven and are controlled by DAC system. The stubs are of 9" size. The minimum lengths that can be achieved by these stubs are $20 \mathrm{~cm}$ and $30 \mathrm{~cm}$ for $3.0 \mathrm{~m}$ and $1.5 \mathrm{~m}$ stub lengths respectively. Variation of the observed value of susceptance in comparison to the theoretical value at $30.0 \mathrm{MHz}$ is shown in figure 9 . Frequency tuning along with the variable stub gives an improvement in the matching. The results are shown for matching at $40.0 \mathrm{MHz}$ with variable stub, which improves when frequency tuning is performed (see figure 10).

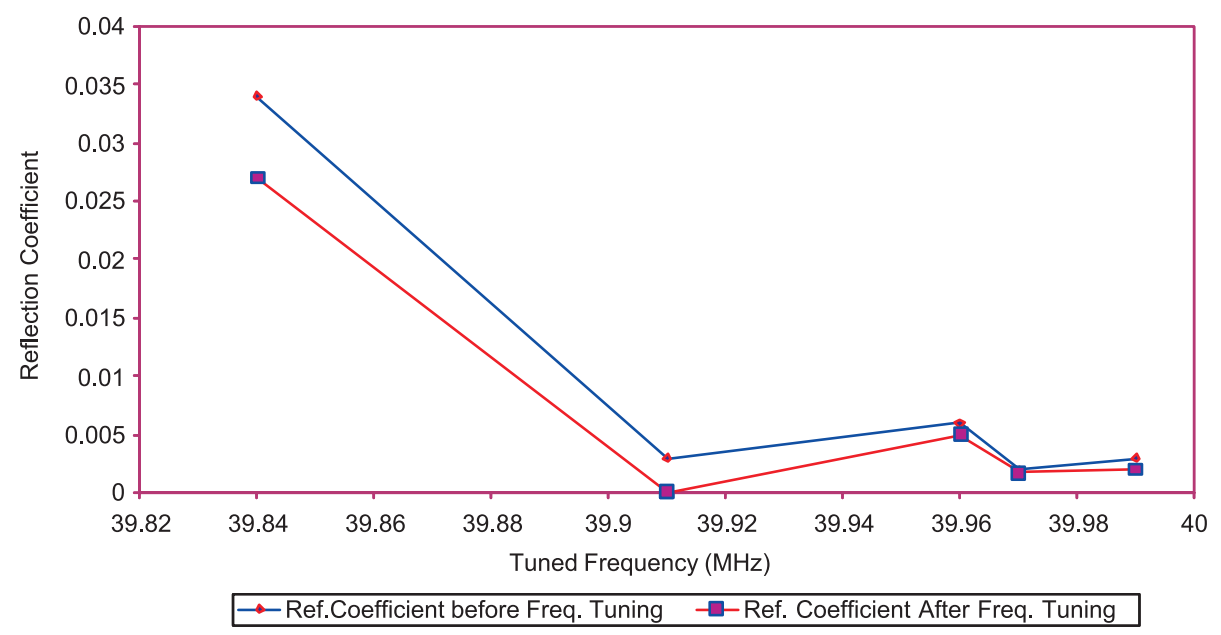

Figure 10. Improvement in impedance matching by frequency tuning at $40 \cdot 0 \mathrm{MHz}$. 


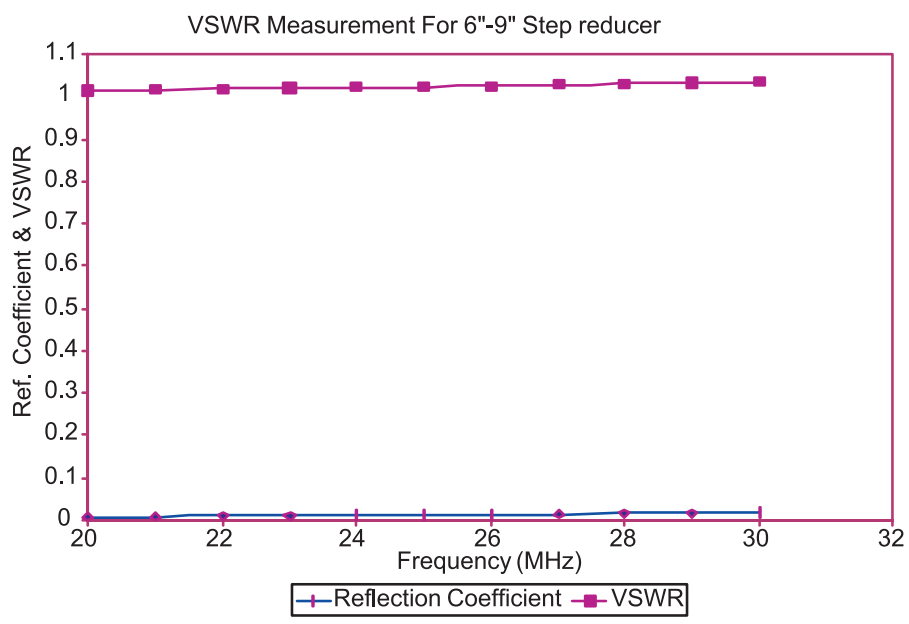

Figure 11. VSWR measurement for 6"-9" step reducer at various frequencies.

The characteristic impedance of the line is about $49.6 \mathrm{ohm}$ at $36.5 \mathrm{MHz}$. The plasma load varies from $1.0 \mathrm{ohm}$ to $10 \mathrm{ohm}$ for the resistive part and $50 \mathrm{ohm}$ to $200 \mathrm{ohm}$ for reactive part. This impedance has been matched with a $50-\mathrm{ohm}$ line over the $20-40 \mathrm{MHz}$ frequency band. The separation between two stubs has been kept to $1 / 8 \lambda$ for measuring all the values of impedance offered by plasma with minimum variation in stub length. Different stub matching has been tested for 3" size stubs. Matching up to $0.7 \mathrm{ohm}$ was done satisfactorily but below this value it was found difficult to match.

\subsection{Step reducers}

The transmission line consists of 6" and 9" sections and the interface is of 8" type, hence transformer sections required are 6" to 9" and 6" to 8" types. The variation of VSWR for 6 "-9" type is shown in figure 11. These transformers are of step reducer type. These values are for $50 \mathrm{ohm}$ characteristic impedance.

\section{Interface}

To connect the antenna to the transmission line, an intermediate line section called the interface is mounted. It has two major tasks: to take up the thermal expansion between the vacuum chamber and the fixed transmission line, and to provide separation between the vacuum of the torus and the pressurized section of the transmission line with two RF vacuum feedthroughs. Mechanical support to the antenna is also provided with the help of the interface. The interface volume is separately evacuated with the help of a turbomolecular pump of capacity $2200 \mathrm{l} / \mathrm{s}$. The ultimate vacuum in this section achieved is $\sim 1 \times 10^{-8}$ torr. The coaxial line of the interface is designed as a tight vacuum line, a combination of an 8-inch and a 5-inch line. The inner and outer conductors, which are UHV compatible, comprise various seamless SS304L tubes. Inner surfaces of outer conductors and outer surfaces of inner conductors are coated with silver $(\sim 50 \mu)$ to reduce RF loss. The most critical items of the interface are as follows.

1) To provide $5 \mathrm{~cm}$ radial movement, finger contact joints on the inner conductor and two bellows in the outer conductor are used. One bellow is part of a vacuum encasement while 


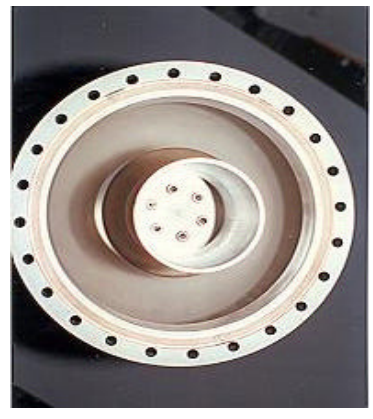

Figure 12. (a) Assembled view of a feedthrough.

the other bellow is part of the Tx-line, which is designed carefully as RF current flows through this. Since the bellow has a large number of convolutions on the inner side, there is a chance for mismatch and power may be reflected back from this location. To avoid mismatch, a RF contact of flexible type (Be-Cu made) has been used inside the bellow.

2) Vacuum barrier between the vacuum vessel and the main transmission line is provided by two high power vacuum feedthroughs. It is made using a cylindrical ceramic barrier brazed between tapered inner and outer coaxial conductors. The assembled view of a feedthrough is shown in figure 12a. Care has been taken to maintain constant characteristic impedance (closely matches the characteristic impedance of the main Tx-line) along the length of the feedthrough by proper adjustment of the tapered angles of the conductors, which minimizes the voltage-standing-wave ratio (VSWR) and eliminates internal reflections. The ceramic cylinder is longer than its diameter. In this case, contours for constant potential and electric field would be nearly parallel and perpendicular to the surface of the ceramic (figure $12 \mathrm{~b}$ ) respectively. The possibility of surface breakdown can thereby be substantially reduced.

3) The torque ring (figure 13) composed of an $\mathrm{Al}_{2} \mathrm{O}_{3}$ disk in between outer and inner conductors is capable of taking EM forces during plasma disruption. Estimated maximum torque is $102.4 \mathrm{Nm}$, which should be released very close to the antenna. Torque ring is designed to meet this requirement.

Since antenna and interface are necessarily vacuum insulated, their RF electric field strength depends mainly on the residual gas pressure. Electric breakdown in vacuum can occur as a result of electron emission at high field strength. This hardly occurs in ICRH system
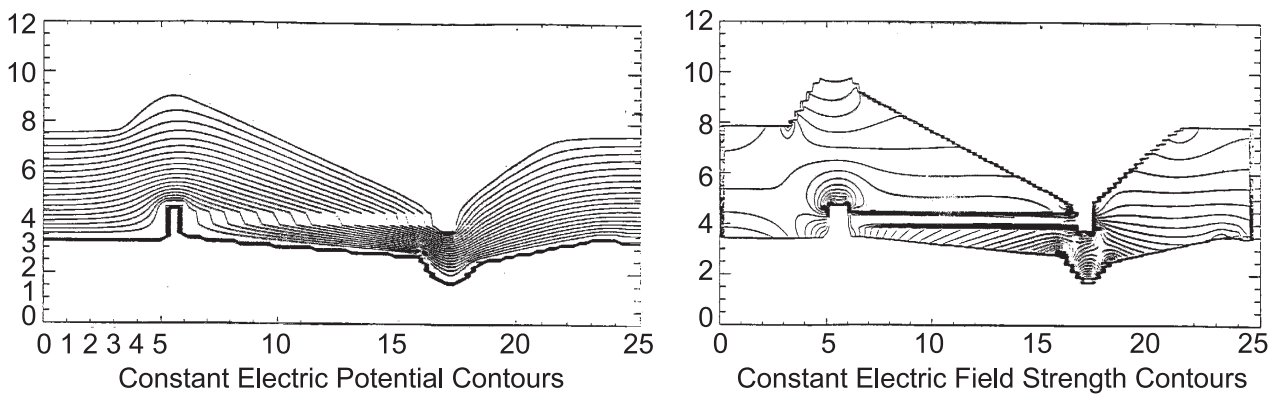

Figure 12. (b) Contours for electric potential and electric field of vacuum feedthrough. 


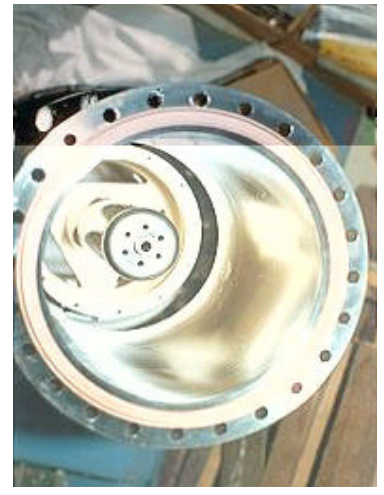

Figure 13. A view of the assembled torque ring inside the interface.

components since the electric fields are kept far below critical values by an adequate design. By careful design, discharges along the insulator surfaces are avoided at the vacuum feedthroughs. Electric breakdown may occur for the Pachen limit for self-sustaining discharges, which cannot be avoided by designing alone, since during the RF operation, sufficient amount of gas can be released from the surfaces to allow breakdown. The surfaces of all metals and ceramics normally adsorb sufficient gas to achieve high pressure. Gas can be desorbed by surface heating due to RF losses and multipactor discharges during which the absorbed gas is released by bombarding the walls with electrons.

RF system is usually conditioned by applying low power short pulses for few hours. Baking at $100^{\circ} \mathrm{C}$ of the interface components is possible as vacuum seals can withstand such temperature. Ten pulses that comprise $100 \mathrm{~ms}$ ON time and $50 \mathrm{~ms}$ OFF time, are usually used for conditioning of Aditya interface and antenna structure. Typical conditioning scenario using $6.9 \mathrm{~kW}$ of RF power is shown in figure 14.

\section{Antenna}

Antenna and the interface described above are capable of handling $200 \mathrm{~kW}$ of RF power at $20-40 \mathrm{MHz}$. The aim is to heat via the 2 nd harmonic of the majority species and pre-ionization for a wide band of frequency range $(20-40 \mathrm{MHz})$.

Fast magnetosonic wave heating scheme is adopted for heating Aditya plasma, since it has several promising damping mechanisms. The antenna is a very sensitive part of any RF system since it has to launch the desired wave structure and constitute the interface with the plasma. For excitation of fast magnetosonic wave inside the plasma, it is necessary to create either a

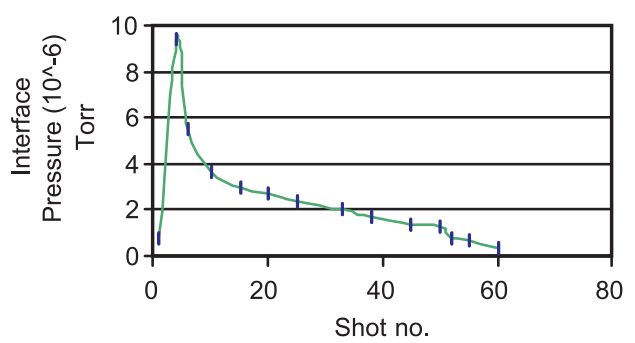

Figure 14. Conditioning of Aditya interface. 
toroidal component of the RF magnetic field or a poloidal component of the RF electric field near the plasma boundary. Poloidal antennae in form of loops or half-loops are widely used to excite the fast wave. ICRH antenna impedance is very sensitive to plasma density at the edge of the plasma that may vary with many parameters, such as antenna-plasma distance, MHD activity, plasma density and transition of the plasma to H-mode.

A powerful 3D code BRACC (BRussels Antenna Coupling Code) (Koch et al 1986) is used to study the antenna plasma coupling efficiency and propagation characteristics inside the plasma volume. Percentage of absorbed power to different plasma species is determined using SWHAP (Simulator of Waves in Hot Anisotropic Plasmas) code (Van Eester 1992). The antenna is designed to launch $200 \mathrm{~kW}$ of RF power to ohmically heat the Aditya plasma to $400 \mathrm{eV}$ (Mukherjee et al 1997). Major and minor radii for Aditya tokamak are $75 \mathrm{~cm}$ and $25 \mathrm{~cm}$ respectively. Main poloidal limiters are kept at $\pm 25 \mathrm{~cm}$ to limit the plasma. The ICRH antenna is placed at the low field side in the shadow region of the poloidal limiter to avoid heavy conducted heat load from the plasma. A fast wave antenna mounted inside Aditya vacuum vessel is shown in figure 15. It consists of central conductor, return conductor (basically the back plate of the antenna box), electrostatic screen (Faraday Shield) and side limiters that protect the antenna system from energetic particles. They are appropriately shaped to make the particle flux density uniform.

The impedance of the antenna has an important effect on its efficiency and maximum power. Active component of the impedance is made of loss resistance, $R_{l}$ and load resistance, $R_{L}$. For efficient operation, $R_{L}>R_{l} . R_{L}$ is a function of the antenna aspect ratio $l / w$, which is kept at 3 for Aditya antenna, corresponding to a power density of $0.66 \mathrm{~kW} / \mathrm{cm}^{2}$. Reactive component of the impedance determines the voltages on the antenna and on the input line. Peak RF power fed to the antenna depends on the maximum voltage that can be handled by the antenna. Variation of antenna impedance with frequency is shown in figure 16. A figure of merit called antenna coupling efficiency $\eta$ gives the ratio of the power effectively coupled to the plasma to the power coupled to the antenna. Calculated $\eta$ at $21.7 \mathrm{MHz}\left(B_{t}=0.7 \mathrm{~T}\right)$ and $30.4 \mathrm{MHz}\left(B_{t}=1.0 \mathrm{~T}\right)$ are 76 and $79 \%$ respectively.

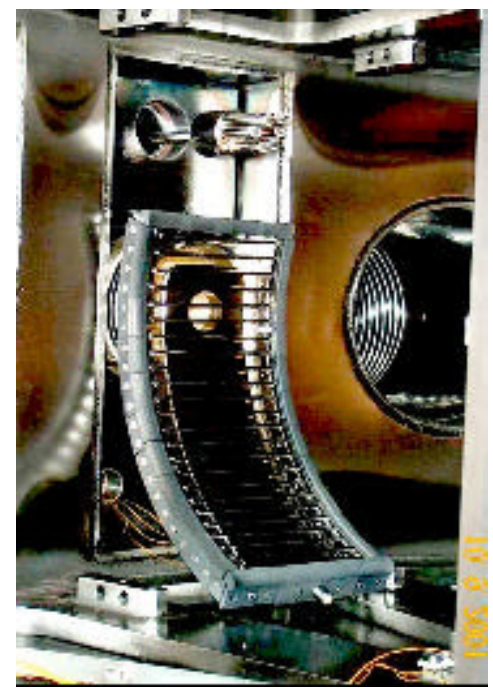

Figure 15. Antenna mounted inside Aditya vacuum vessel. 

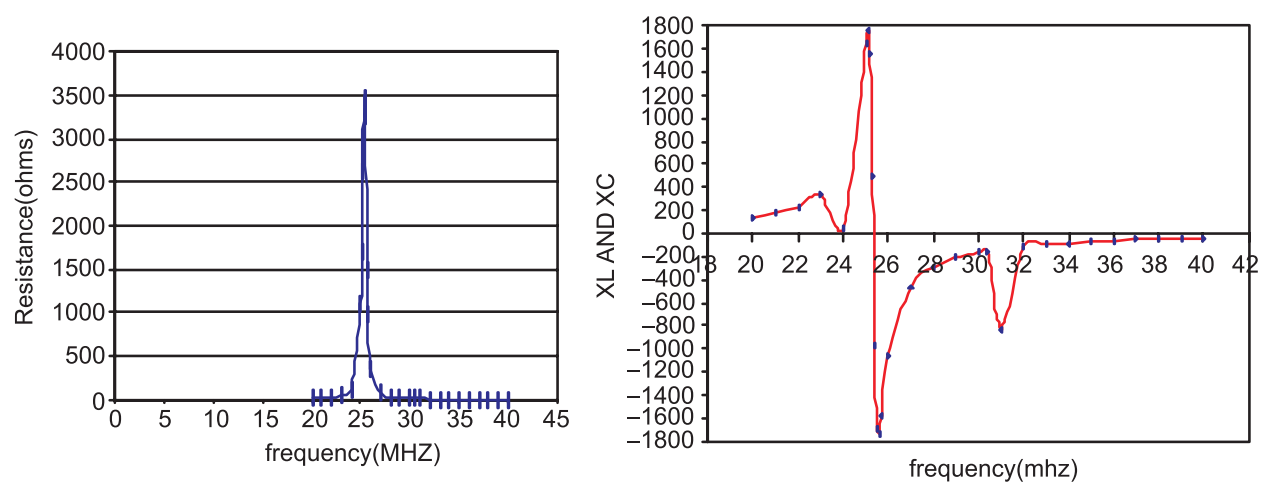

Figure 16. Antenna impedance variation with frequency.

Impurity generation by the antenna during operation is negligible. Disruption stresses on the antenna assembly are estimated. Side plates of the antenna assembly experience force in the vertical direction by $f_{y}=I_{\text {total }} B_{t}=15.05 \mathrm{kN} / \mathrm{m}$. Moment $M_{x}$ transmitted to the outer conductor of the transmission line is $102.4 \mathrm{Nm}$ which reflects in the design of torque ring (described in Interface section). Thermal calculation shows that antenna could be safely operated for pulsed operation without cooling.

\section{High voltage DC (HVDC) power supplies}

High voltage DC power supplies are required to generate or amplify RF power with the help of various tubes. Each amplification stage is fed by a separate HVDC power supply with protections for over-current, tube arcing, soft start etc. As several stages cascaded and each stage consists of many power supplies they need to be suitable for remote control and monitoring operations. Desired on/off sequence of these power supplies is ensured with hardwired interlocks. Some important power supplies are described separately below.

\subsection{HVDC power supplies for pre-driver ( $2 \mathrm{~kW})$ and driver $(20 \mathrm{~kW})$ stages}

These power supplies are used to feed the triode 3CX5000A7 for $2 \mathrm{~kW}$ stage amplifier and the triode $3 \mathrm{CW} 30000 \mathrm{H} 7$ for $20 \mathrm{~kW}$ stage amplifiers. These RF amplifiers are designed to operate in grounded grid mode. Grounded grid mode demands that the +ve end of the HVDC supply be connected to the anode of the RF amplifier tube and the - ve end to be floated to around $100 \mathrm{~V}$ or $200 \mathrm{~V}-\mathrm{ve}$, with respect to the grid, which is grounded. Hence, it is required to provide a floating HVDC power supply for both pre-driver and driver stages. Experimental results show that triodes are very prone to parasitic oscillation and to avoid oscillations, the HVDC power supply needs to have good dynamic response with minimum overshoot and undershoot. The voltage ripple must be low in order to minimize fluctuations in the RF output and good line and load regulation are required to get constant RF power. Voltage ripple and line and load regulation of $<1 \%$ have been achieved in these HVDC supplies.

A very important requirement is to switch off the power supply within a few microseconds, in case of arcing inside the tube or in the transmission line. The fast switch-off capability of the HVDC power supplies limits the energy deposited to the arc and protects the tube from complete destruction. The power supplies also have several interlocks, which ensure safety 
Table 3. Functional requirements of HVDC power supplies.

\begin{tabular}{lcc}
\hline Parameters & $2 \mathrm{~kW}$ stage power supply & $20 \mathrm{~kW}$ stage power supply \\
\hline Supply type & Floating & Floating \\
Voltage range & $1 \mathrm{kV}$ to $4 \mathrm{kV}$ & $8 \mathrm{kV}$ \\
Current & $1 \mathrm{Amp}$ & $6 \mathrm{Amp}$ \\
Switch off time & $2 \mu \mathrm{Sec}$. & $<2 \mu \mathrm{Sec}$. \\
\hline
\end{tabular}

of the tube and operating personnel. They can be operated and monitored locally or remotely from the central control system.

The operating parameters of the power supplies are listed in table 3.

\subsection{HVDC power supply for output (200 kW) stage}

This HVDC power supply is used to feed the plate of $200 \mathrm{~kW}$ RF generator, i.e the tetrode 4 CM $300000 \mathrm{GA}$. This tetrode tube also operates in grounded grid mode. Therefore, a floating HVDC power supply is used for the $200 \mathrm{~kW}$ stage as well.

The first requirement of the HVDC power supply is to provide different DC voltages in a specified range of $8-15 \mathrm{kV}$. Another important requirement is that the power supply must be able to give adequate protection to the tube during arcing. The size of the filter capacitors must be optimized in order to have minimum stored energy, low ripple and good regulation. The power supply system as a whole should have high reliability to deliver RF power.

Table 4 gives the absolute maximum ratings and typical operating parameters of the tetrode tube used for the $200 \mathrm{~kW}$ RF generator. An existing HVDC power supply from M/s Brentford Co., England is used for this purpose. Some modifications as listed below have been included in an existing power supply, to make it suitable for the $200 \mathrm{~kW}$ RF generator.

(a) $11 \mathrm{kVAC}$ voltage variation system: This system provides a continuously variable AC input to the HVDC power supply. The motorized remotely controlled system enables smooth increase of plate voltage to the required operating level.

(b) Control scheme modification: Continuously variable input of 0 to $11 \mathrm{kV}$ enables soft charging of the filter capacitors. Hence, the redundant pre-charging circuit of the capacitors, to avoid high inrush currents at the time of switching, and related interlocks are removed from the circuit.

(c) Current monitoring and interlock: Pulse current transformer (pulse CT) and Hall effect DC current transducer (DCCT) are used for monitoring and interlock purposes. Pulse CT

Table 4. Absolute maximum ratings of HVDC power supply.

\begin{tabular}{lcc}
\hline Parameters & Absolute maximum values & Typical operating parameters \\
\hline DC plate voltage & $15 \mathrm{kV}$ & $12 \mathrm{kV}$ \\
DC plate current & $40 \mathrm{amps}$ & $30 \mathrm{amps}$ \\
Plate dissipation & $300 \mathrm{~kW}$ & $95 \mathrm{~kW}$ \\
Grid dissipation & $2 \mathrm{~kW}$ & $600 \mathrm{~W}$ \\
Screen dissipation & $5 \mathrm{~kW}$ & $4 \mathrm{~kW}$ \\
\hline
\end{tabular}




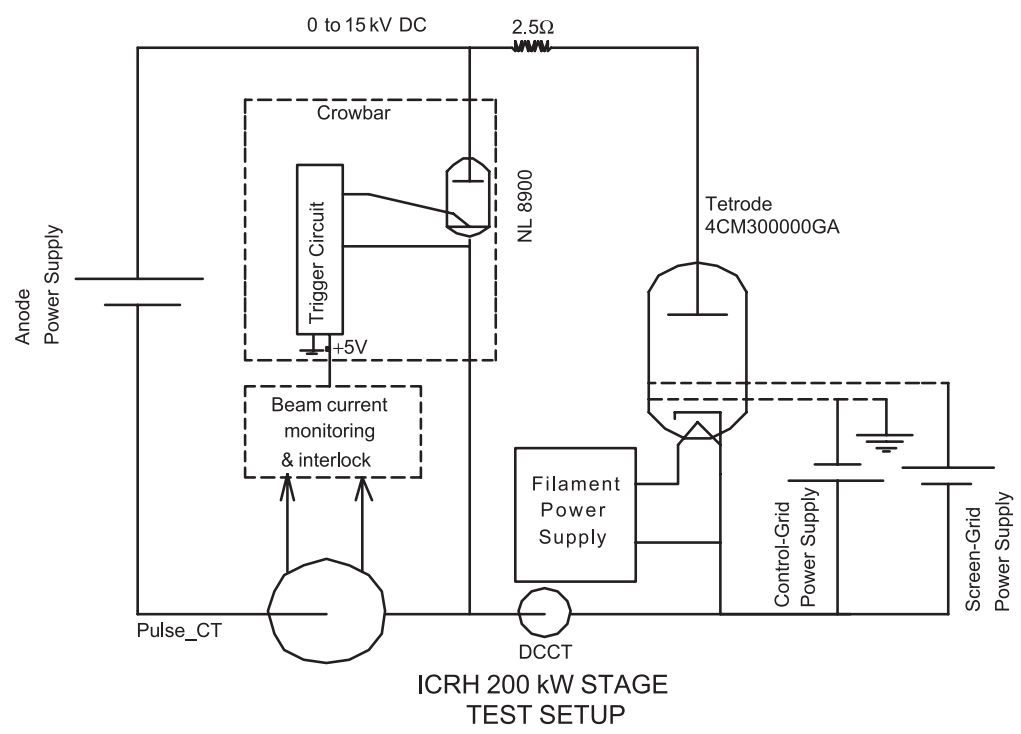

Figure 17. Test setup for $200 \mathrm{~kW}$ stage.

provides effective protection for fast-rising over-current faults such as arc faults. For overcurrent faults of slow rise pulse CT protection alone is inadequate. Therefore, a DCCT (figure 17) is used for effective protection for slow rising and sustained over-current faults that can occur during long duration shots. DCCT signal is also used by the DAC system for the beam current monitoring.

The current signal is processed by the electronic circuitry. The circuit, optimised for minimum delay and reliability, is developed in-house. In the event of over-current detection, it gives a TTL high output and also operates a relay. TTL output is used for the triggering of crowbar and relay contacts interlocked to trip the AC input to the power supply by opening $\mathrm{VCB}$. A delay of $15 \mu \mathrm{s}$ for crowbar signal and $80 \mathrm{~ms}$ for actual $11 \mathrm{kV}$ input interruption is achieved (figure 18b). Block diagram of the electronic circuit is given in figure 18a.

(d) Crowbar: When conventional power supplies feed high power microwave tubes, a reliable crowbar protection system, tested separately to limit the energy, must be used to assure

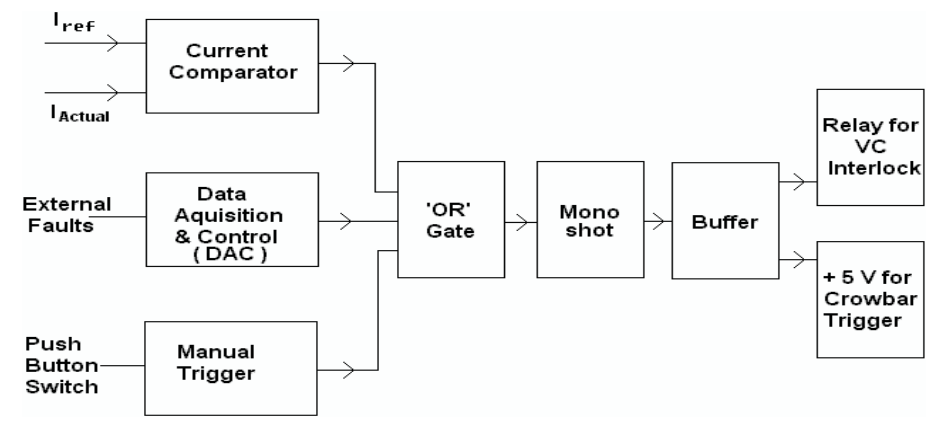

Figure 18. (a) The circuit can generate a crowbar trigger for hard wired external faults, like arc in the transmission line, lon pump over-current etc. through data acquisition control system. 


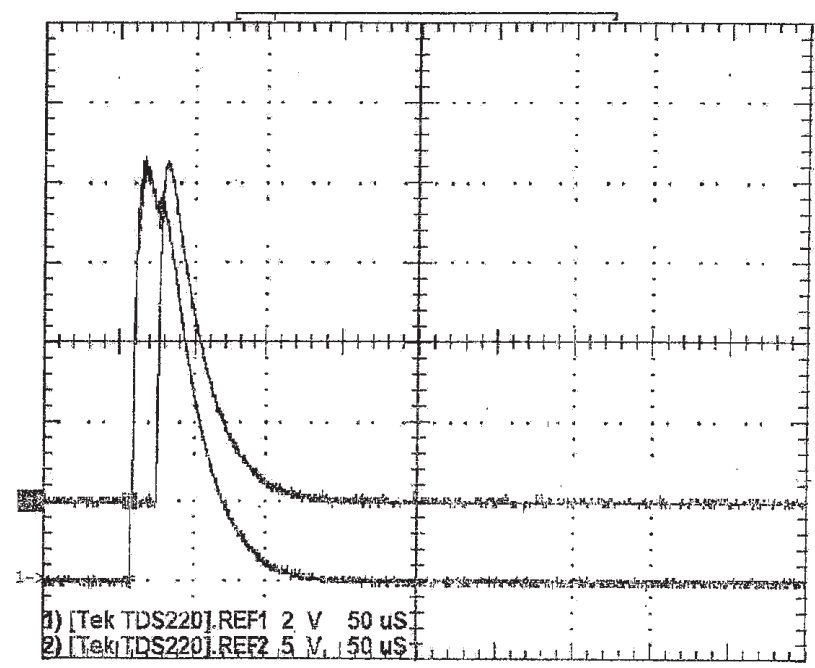

Figure 18. (b) Oscillogram showing delay between current through wire (bottom) and crowbar current: CH1 (bottom): I (wire): $0 \cdot 01 \mathrm{~V} / \mathrm{amp} ; \mathrm{CH} 2$ (top): I (crowbar): $0 \cdot 025 \mathrm{~V} / \mathrm{amp}$.

the tube safety. Crowbar protection for the tetrode is provided with the help of a single ignitron (NL8900). Wire-burn test to assure fault energy of less than 10-joule is performed successfully (figure 18c).

\subsection{Filament power supplies for RF 2, 20, and $200 \mathrm{~kW}$ stage generators}

The filament is used to heat the cathode of the tetrode, which in turn emits electrons. The cold resistance of the filament is very low. Therefore, if the full-rated voltage is applied to the filament instantly, the resultant surge current may burn out the filament. Filament repair involves $50 \%$ cost of the tube. Therefore, damage to the filament is one of the most critical failures of the tube.

The filament voltage of 2 and $20 \mathrm{~kW}$ stages is raised to its full-rated value in steps using resistors and timer circuits. These filament power supplies are housed as an integral part of respective HVPS.

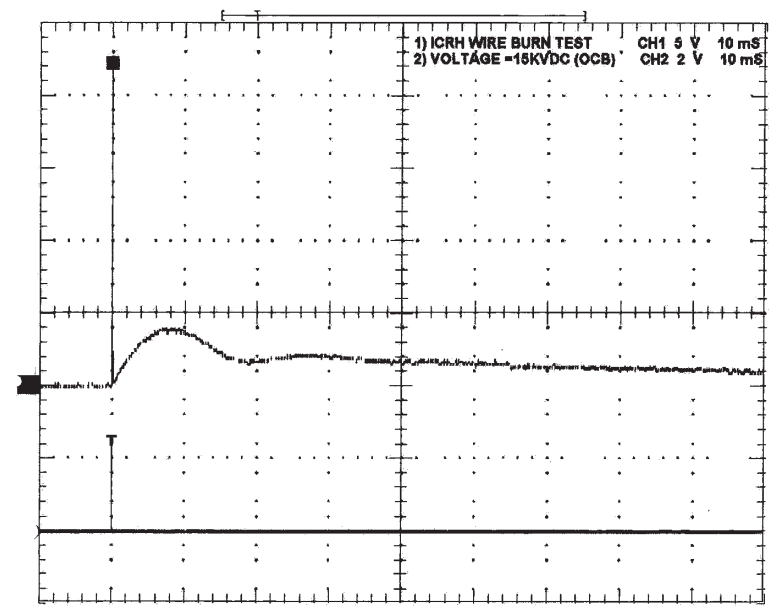

Figure 18. (c) Oscillogram showing current through wire (bottom) and total currents (ignitron current) CH1 (bottom): I (wire): 0.01 V/Amp; CH2(top):I(total):0.025 V/amp. 
The filament supply of $200 \mathrm{~kW}$ stage is rated for $18 \mathrm{~V} \mathrm{AC}_{\mathrm{rms}}$ and $430 \mathrm{~A}_{\mathrm{rms}}$. The voltage is raised to its full-rated value in a ramp fashion. The voltage raising ramp rate is kept at $5 \mathrm{~V} / \mathrm{min}$. The change in the filament voltage changes the output RF power. Hence, it is required to keep the filament voltage within $\pm 3 \%$ of its operating value. This means that the filament voltage must be regulated to a high precision. Over-voltage, under-voltage, over-current and surge-current protections have to be inherent qualities of the power supply. This filament power supply has to be floated over the high voltage power supply of the tube. Therefore, it is required to isolate the filament power supply system from HVDC power supply of the plate. During idle condition of the tube (when the tube is not delivering RF power), the filament voltage has to be reduced to some lower value and held there instead of switching it off. This avoids frequent switching of the filament and increases filament life.

\subsection{Screen grid power supply for $200 \mathrm{~kW}$ stage (1000 $\left.\mathrm{V}_{\mathrm{DC}}, 1 \mathrm{amp}\right)$}

The screen grid of the $200 \mathrm{~kW}$ stage RF amplifier is positively biased in order to minimize the secondary emission. Therefore, the screen bias voltage is +ve DC voltage with respect to cathode. Usually the screen voltage is kept at a fixed point, for a particular operating point of the amplifier. However, the amplifier may need different screen voltages for different operating point. The screen grid power supply must have low voltage ripple in order to have minimum fluctuation in the RF output power.

In addition to over-voltage and over-current protections, the power supply is protected for plate voltage failure. A plate voltage of $\sim 4 \mathrm{kV}$ is required to switch the screen grid power supply ON. Plate voltage falling below this settable value initiates trip of the power supply. An internal thyristor crowbar is interlocked with HVPS crowbar to limit the tube arc fault energy and to protect the screen grid.

\subsection{Control grid power supply for $200 \mathrm{~kW}$ stage ( 0 to $\left.-350 \mathrm{~V}_{\mathrm{DC}}, 1 \mathrm{amp}\right)$}

The control grid of the RF amplifier needs to be biased at different DC voltages. In order to keep the amplifier in the cut-off mode (non-conducting) the control grid is kept at high negative voltage with respect to the cathode typically at $-350 \mathrm{~V}$. To make the amplifier conduct, the control grid voltage is gradually reduced, typically to $-280 \mathrm{~V}$.

The most important feature of this control grid power supply is that it is never intentionally tripped. If the control grid voltage becomes zero, with other voltages at their respective levels, then thermal run away of the amplifier occurs and this in turn may damage the tetrode permanently. Whenever over-voltage or over-load fault occurs, an audio alarm is activated and at the same time a relay is switched for interlocking purpose.

\subsection{Data acquisition and control}

DAC can control all the HVDC power supplies, through signals like raise, lower, start/stop etc. Output voltage and current of HVDC power supplies for 2, 20 and $200 \mathrm{~kW}$ stages are monitored during the RF pulse and can be graphically displayed for analysis.

The $200 \mathrm{~kW}$ stage filament, screen grid and control grid power supplies are also controlled by start/stop signal and their status and screen grid current are monitored.

\section{Data acquisition and control (DAC) system}

To analyse the system performance it is essential to monitor, acquire different system parameters along with an interlocking system to operate the system in failsafe manner. ICRH system 
has its own data acquisition and control (DAC) system to execute the task of data archiving, monitoring, interlocking and control. The analysis of acquired data takes place in off-shot mode. There is off-shot control of the tuning element for maximum coupling of RF power in plasma during subsequent shots.

ICRH DAC system consists of microcontroller based multifunction I/O (MIO) modules. All the modules are connected in mulitdropped RS485 network which is ultimately connected to a PC via RS 485 interface card in ISA bus. Signals from different subsystem undergo signal conditioning and are fed to the MIO modules. Signals are digitized in MIO and used for the purpose of data acquisition, which is done by external trigger or by S/W trigger in the MIO modules.

Two stubs, one fixed phase shifter and one variable phase shifter are connected to transmission line to match impedance between load (antenna) and generator. Twenty-two probe signals are used to calculate VSWR from which variable length of stubs and phase shifter are calculated and changed using position controllers which are connected to host computer via RS-485 network using other port.

MIOs are distributed physically in Aditya hall and in RF-lab control room. The essence of distribution is that MIOs in the hall can handle the signals from ICRH subsystems housed in the hall such as transmission line, interface section, plasma edge diagnostics. The MIOs in the RF lab take care of the signals from DC power supplies of the RF generator, RF power signals from different stages of the RF generator, cooling channels and SPDT switch. Interconnections between MIO/DIO are shown in figure 19.

There are total 8 MIOs and one DIO in ICRH DAC system. DIO controls the MIO activity and also offer facility of interlocking, monitoring of the connected signals. Each MIO has 8 AI/P, 2 AO/P, 8 DI/P (7 I/P and 1 "low pulse" for external triggering at MIO), 8 DO/P, 4 lines for serial communication and power supplies $( \pm 12 \mathrm{~V}$ and $+5 \mathrm{~V})$.

ICRH DAC system operates in two different modes: (i) Stand-alone mode and (ii) masterslave mode. In stand-alone mode ICRH DAC system operates independently and the RF generator is connected to the matched (dummy) load. In this mode, the RF generator dumps the power in the dummy load. DAC system gives the S/W trigger to take RF shots and data archiving for pre-defined time is executed.

In master-slave mode, the RF system is connected to the Aditya plasma and ICRH DAC system operates in slave mode with the Aditya control system. After checking of various required power supplies and cooling system status, ICRH DAC system sends a READY signal to Aditya control system to trigger ICRH DAC system for data acquisition and taking RF shot. The archiving duration is predefined in ICRH DAC system. The setting of shot duration is provisional, like duration could be set by Aditya timer or through ICRH DAC system timer.

At present Aditya control system gives a trigger that is opto-isolated. With respect to this trigger an adjustable delayed trigger is generated and fed to the DIO terminal \# 47 termed "Trigger from Aditya". This trigger activates all the MIO data acquisition and generates a pulse of predefined time ("post-trigger" time) duration at DIO terminal \# 66. This pulse is fed to the LPA. Pre- and post-trigger time duration has to be set before pressing the "Start" button and wait for the Aditya trigger to work.

\subsection{Interlock circuit}

There are three levels of interlock circuit used in ICRH system.

(1) RF interlock: There is a hardwired interlock circuit, which takes care of the tetrode safety. The fault signals from field first conditioned with the help of signal processing and isolation 


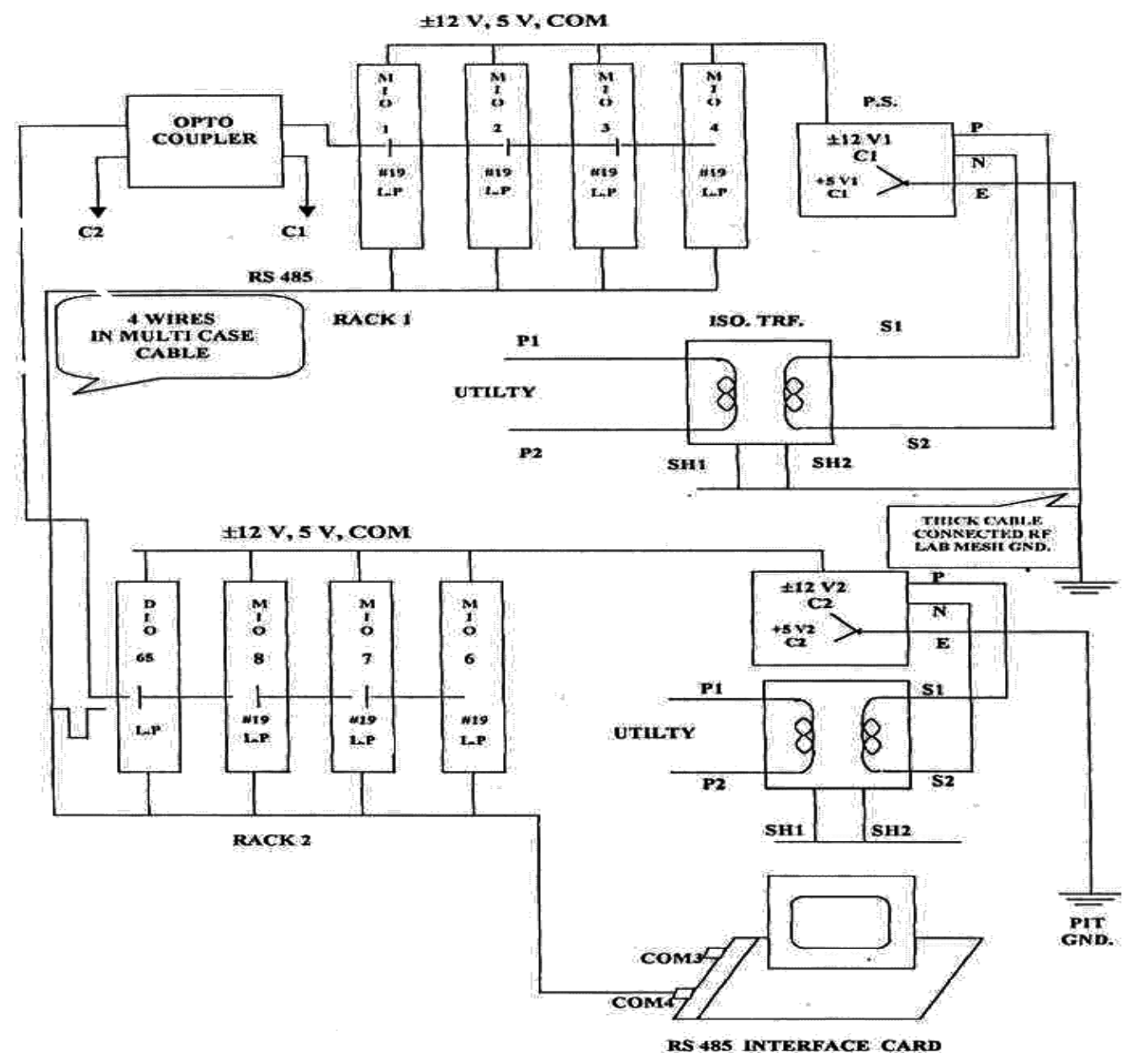

Figure 19. $\mathrm{MIO} / \mathrm{DIO}$ connection diagram.

cards and bifurcated. One of which is taken to the MIO terminal for monitoring and the other is taken to interlocking circuit.

Interlocking circuit accepts the TTL level signals. All the fault signals are normally TTL "L". At fault condition the level of the signal goes " $H$ " which turns Off the RF switch within $10 \mu$ s and switches off the DC supplies of the tube in parallel. Figures 20a and figures $20 \mathrm{~b}$ describe the schematic circuit diagrams. Inputs to the Interlock card are:

- Screen grid On/Off

- Control grid On/Off

- Control grid UV

- Control grid OC

- Filament On/Off

- VCB on/off

- Water flow in $200 \mathrm{~kW}$

- Pre-driver stage TRIP

- Driver stage ready 


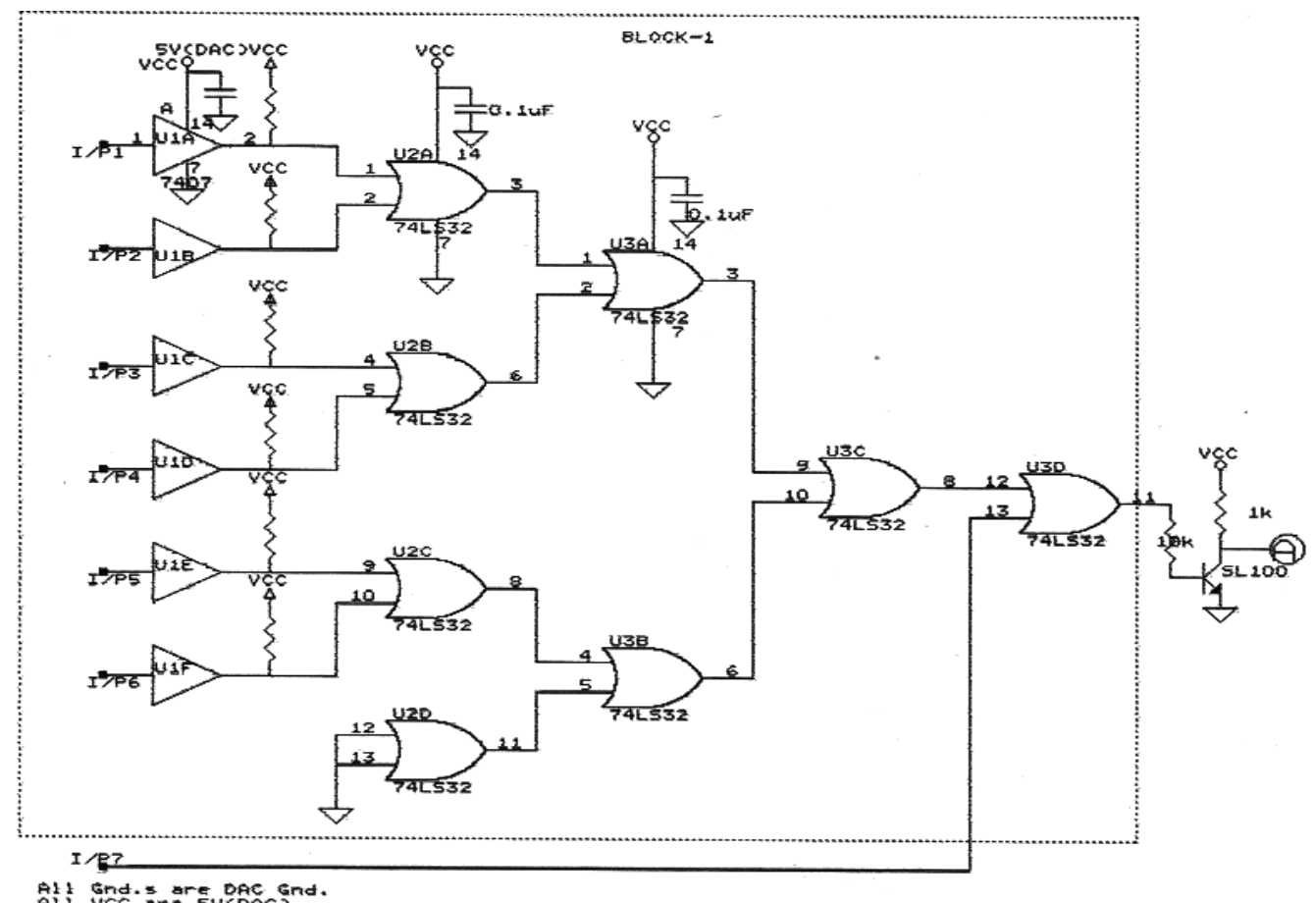

Figure 20. (a) RF interlock circuit.

All these signals have been ORed and a single output has been generated which is then latched and used for removing the RF switch in the fast-time scale (within $10 \mu \mathrm{s}$ ) and high voltage DC power supplies in sequence using following output signal.

Output channels are:

CH1: RF switch On/Off (local trigger for LPA)

CH2: PD stage PS Start/Stop ( $2 \mathrm{~kW})$

CH3: Driver stage PS Start/Stop $(20 \mathrm{~kW})$

CH4: O/P stage PS (VCB) Start/Stop (200 kW)

(2) Interlock of screen grid power supply with HVPS: Screen grid should be switched on only when predefined voltage exists at the plate (HVPS). If it goes down SG should be switched off within few milliseconds (relay-operated). Plate voltage is acquired after optical isolation. It is compared with the reference and comparator $\mathrm{o} / \mathrm{p}$ controls the screen grid supply.

(3) Filament interlock with water-cooling:

This interlock checks the waterflow level. As soon as flow level goes down, filament is switched off and the fast interlock operation is initiated.

\subsection{Signal processing card description}

Signals from different subsystems should be processed at the field end before carrying them to the MIO. In case of digital I/O signals there are two types of signals: (i) Potential 


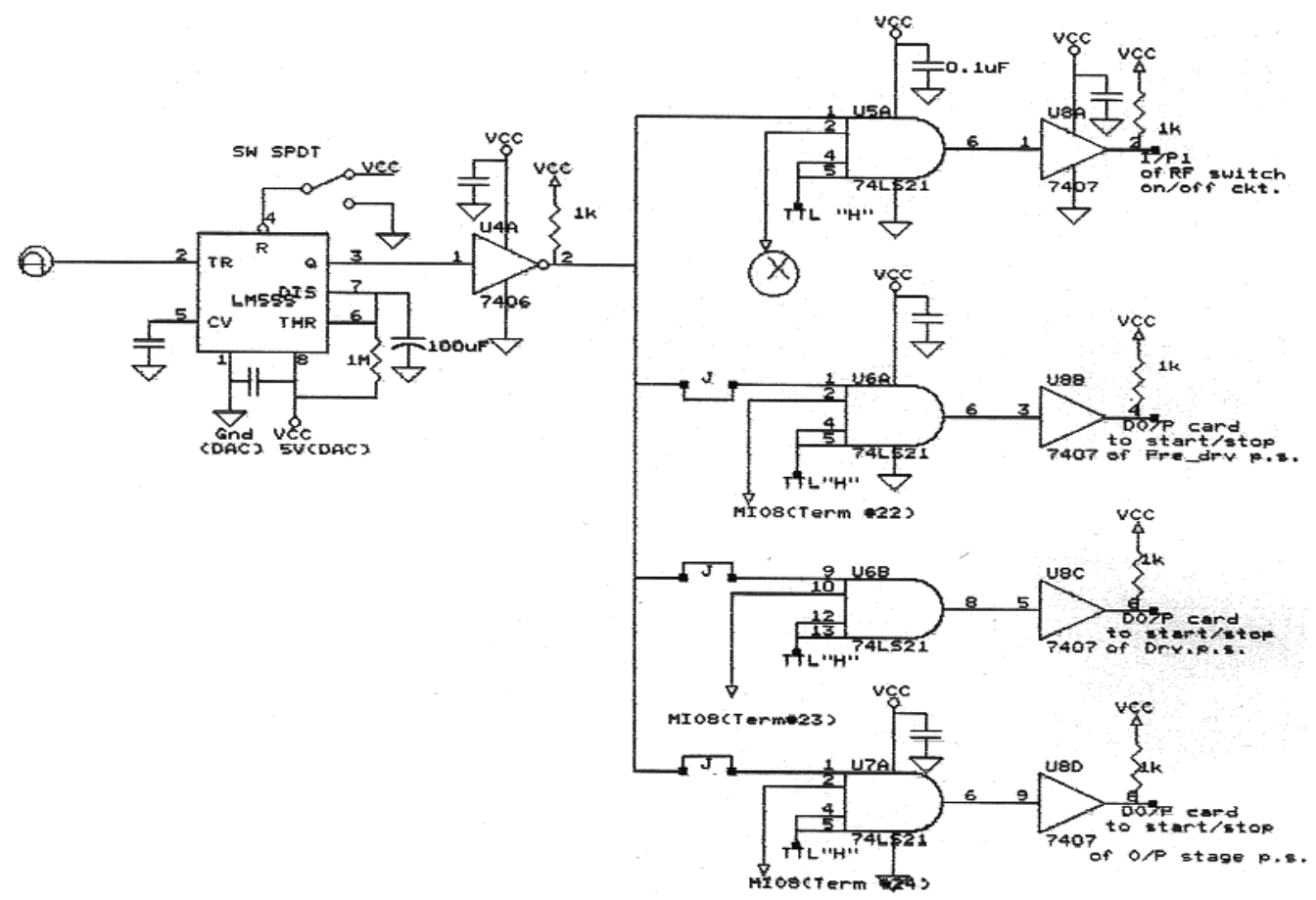

Figure 20. (b) RF interlock circuit.

free contact from different relays of different subsystems, (ii) direct digital input signals of TTL level. These two types of signals are opto isolated and converted to an open collector $\mathrm{O} / \mathrm{P}$.

All analog signals are optically isolated, converted to $0-5 \mathrm{~V}$ level and connected to $\mathrm{MIO} / \mathrm{DIO}$ through shielded twisted pair cable. Optical isolation increases the noise immunity of the system by providing the ground loop isolation and to some extent high voltage isolation $(1-2 \mathrm{kV})$.

\subsection{Power measurement}

To measure forward and reflected power RF detector is connected at the directional coupler output. Detector output is scaled down to 0 to $1 \mathrm{~V}$ level and connected to a Knick amplifier (galvanic isolation amplifier) for isolation. Output from the Knick amplifier is connected to MIO pin for digitization and storage. Lookup table is used to display the power level in kilowatts for off-line graph plotting and on-line screen display-purpose.

\subsection{V-I converter}

To convert 0-20 mA current signals into 0-5 V signal, current signal is terminated by $500 \Omega$ resistors and is converted into voltage by I/V converter using opamp OPA27. The differential configuration of the I/V converter circuit is to make noise-free conversion and all common mode signals are rejected. 


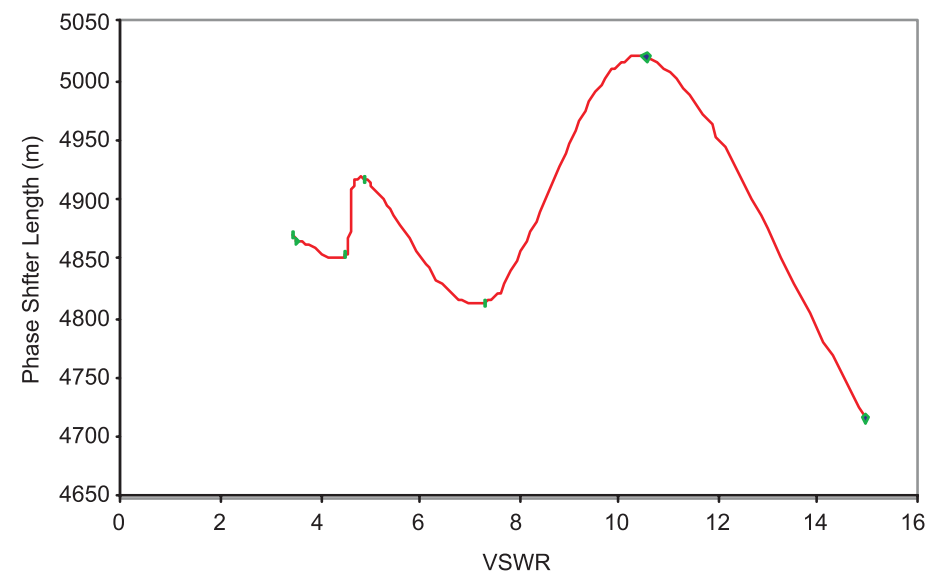

Figure 21. Impedance matching on Aditya using twenty probes and directional coupler at load end.

\section{Preliminary results and conclusion}

Antenna system is matched with RF generator using matching unit comprising stubs and phase shifters. Twenty voltage probes are placed in between the antenna system and the matching unit where VSWR is quite high. RF power coupled to the antenna has been optimized at $25.5 \mathrm{MHz}$. This is done off-line based on the signal obtained from the directional coupler positioned at load end and the signals from the twenty probes to measure the VSWR.

Antenna current is measured using a calibrated current loop placed at the back of the antenna box. Antenna current for a $100 \mathrm{~ms}$ typical shot is shown in figure 22 .

A probe assembly consisting of electric dipoles, magnetic loops, Langmuir probes and capacitive probe is placed inside the Aditya vacuum chamber through the radial port. This assembly can be moved by $50 \mathrm{~mm}$ to scan mainly the SOL region. RF electric and magnetic field components are measured using dipoles and magnetic loops. A typical shot for dipole and loop is shown in figure 23. The same heating system is used to experiment on plasma breakdown and pre-ionization to help ohmic breakdown.

In conclusion, a $200 \mathrm{~kW}$ plasma heating system at $20-47 \mathrm{MHz}$ has been successfully commissioned on Tokamak Aditya and initial experiments have started. The generator has been operated at full power for $10 \mathrm{~s}$ on water dummy load.

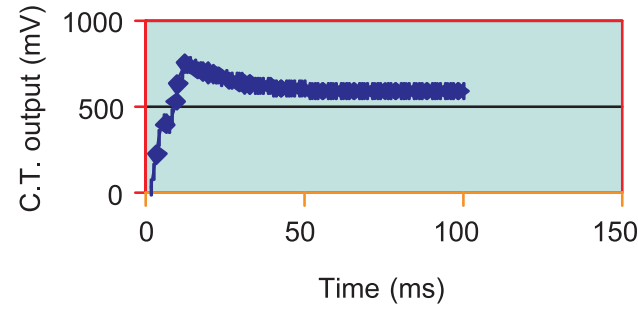

Figure 22. Typical antenna current monitored using non-standard C.T. 
(a)

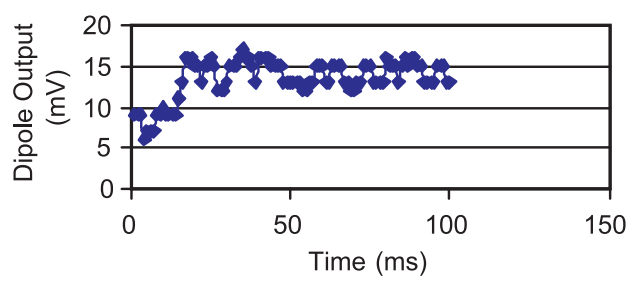

(b)

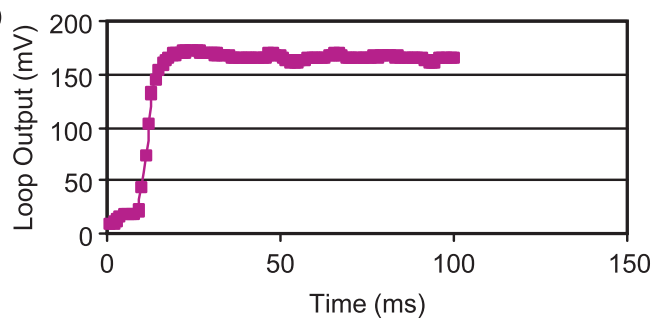

Figure 23. Signal from electric dipole (a) and magnetic loop (b).

Authors would like to thank Dr P K Kaw for his constant support during the project. One of the authors (DKB) would also like to thank Dr B K Sinha for his support and encouragement. Authors would like to thank Dr P I John for his contribution to the project during the initial stage and constant encouragement thereafter.

\section{References}

Adam J et al 1974 Wave generation and heating in the ST-tokamak at the fundamental and harmonic ion cyclotron frequencies. Plasma Physics and controlled Nuclear Fusion Research (Proc. 5th Int. Conf. Tokyo, 1974) 1: 65-73

Bhatt S B et al 1989 ADITYA: The first Indian tokamak. Indian J. Pure Appl. Phys. 27: 710-742

Dolan T J 1982 Fusion research (London: Pergamon)

Koch R, Bhattnagar V P, Messiaen A M, Van Eester D 1986 A global solution of the ICRH problem based on the combined use of a planar coupling model and hot-plasma ray-tracing in tokamak geometry. Comput. Phys. Commun. 40: 1-22

Mukherjee A, Singh J P, Bora D 1997 Fast wave antenna design for ADITYA tokamak. Technical Report No. IPR/TR-59/97: 1-26

Van Eester D 1992 Simulator of waves in hot anisotropic plasmas. Proc. Europhysics Topical Conf. on Radio Frequency Heating and current Drive, EPS Conference Abstracts 16E: 129

Vdovin V L et al 1974 Plasma heating with an azimuthally non-symmetrical ion cyclotron wave in tokamak TM-1-HF. Plasma Physics and Controlled Nuclear Fusion Research (Proc. 5th Int. Conf. Tokyo, 1974) 1: 217-225

Uckan N A et al 1989 ITER Physics design guideline. ITER documentation series, No. 10 (Vienna: IAEA) pp 9-41 